NBER WORKING PAPER SERIES

HOUSE PRICE BOOMS AND THE CURRENT ACCOUNT

\author{
Klaus Adam \\ Pei Kuang \\ Albert Marcet \\ Working Paper 17224 \\ http://www.nber.org/papers/w17224
NATIONAL BUREAU OF ECONOMIC RESEARCH
1050 Massachusetts Avenue
Cambridge, MA 02138
July 2011

We thank Lars Hansen, Michael Woodford and Daron Acemoglu for useful comments. All errors are our own. Marcet acknowleges funding from Research project number ECO2008-04785, Plan Nacional, Ministerio de Educación y Ciencia, Spain, and Generalitat de Catalunya. The views expressed herein are those of the authors and do not necessarily reflect the views of the National Bureau of Economic Research.,

NBER working papers are circulated for discussion and comment purposes. They have not been peerreviewed or been subject to the review by the NBER Board of Directors that accompanies official NBER publications.

(C) 2011 by Klaus Adam, Pei Kuang, and Albert Marcet. All rights reserved. Short sections of text, not to exceed two paragraphs, may be quoted without explicit permission provided that full credit, including $\odot$ notice, is given to the source. 
House Price Booms and the Current Account

Klaus Adam, Pei Kuang, and Albert Marcet

NBER Working Paper No. 17224

July 2011

JEL No. E44,F32,F41

\begin{abstract}
$\underline{\text { ABSTRACT }}$
A simple open economy asset pricing model can account for the house price and current account dynamics in the G7 over the years 2001-2008. The model features rational households, but assumes that households entertain subjective beliefs about price behavior and update these using Bayes' rule. The resulting beliefs dynamics considerably propagate economic shocks and crucially contribute to replicating the empirical evidence. Belief dynamics can temporarily delink house prices from fundamentals, so that low interest rates can fuel a house price boom. House price booms, however, are not necessarily synchronized across countries and the model is consistent with the heterogeneous response of house prices across the $\mathrm{G} 7$ following the reduction in real interest rates at the beginning of the millennium. The response to interest rates depends sensitively on agents' beliefs at the time of the interest rate reduction, which in turn are a function of the country specific history prior to the year 2000 . According to the model, the US house price boom could have been largely avoided, if real interest rates had decreased by less after the year 2000 .
\end{abstract}

Klaus Adam

University of Mannheim

Dept. of Economics

L7,3-5

68131 Mannheim

Germany

adam@mail.uni-mannheim.de

Pei Kuang

Goethe University of Frankfurt

Departmnet of Economics

Campus Westend - Grüneburgplatz 1,

60629 Frankfurt am Main

Germany

Kuang@finance.uni-frankfurt.de

\author{
Albert Marcet \\ Department of Economics \\ London School of Economics \\ Houghton Street \\ London WC2A $2 \mathrm{AE}$ \\ United Kingdom \\ a.marcet@1se.ac.uk
}




\title{
House Price Booms and the Current Account*
}

\author{
Klaus Adam \\ Mannheim University and CEPR \\ Pei Kuang \\ University of Frankfurt
}

\author{
Albert Marcet \\ London School of Economics, CEP and CEPR
}

July 3, 2011

\begin{abstract}
A simple open economy asset pricing model can account for the house price and current account dynamics in the G7 over the years 2001-2008. The model features rational households, but assumes that households entertain subjective beliefs about price behavior and update these using Bayes' rule. The resulting beliefs dynamics considerably propagate economic shocks and crucially contribute to replicating the empirical evidence. Belief dynamics can temporarily delink house prices from fundamentals, so that low interest rates can fuel a house price boom. House price booms, however, are not necessarily synchronized across countries and the model is consistent with the heterogeneous response of house prices across the G7 following the reduction in real interest rates at the beginning of the millennium. The response to interest rates depends sensitively on agents' beliefs at the time of the interest rate reduction, which in turn are a function of the country specific history prior to the year 2000. According to the model, the US house price boom could have been largely avoided, if real interest rates had decreased by less after the year 2000 .
\end{abstract}

JEL Class. No: F41, F32, E43

\section{Introduction}

We present a stylized open economy asset pricing model with rationally investing households that can quantitatively replicate the house price dynamics in the G7 economies over the years 2001-2008, as well as the associated dynamics of the current account.

\footnotetext{
${ }^{*}$ We thank Lars Hansen, Michael Woodford and Daron Acemoglu for useful comments. All errors are our own. Marcet acknowleges funding from Ministerio de Educación y Ciencia and Generalitat de Catalunya. Contacts: adam@uni-mannheim.de, a.marcet@lse.ac.uk and pei.kuang@hof.uni-frankfurt.de.
} 
In our model, boom and bust dynamics in house prices are triggered by macro-fundamentals, e.g., changes in real interest rates or housing preferences but, as in the data, the response to these changes in fundamentals can vary across countries. Also similar to the data, price booms in our model are associated with an expansion of the housing stock, a deterioration of the current account, and a consumption boom, while the subsequent house price declines are accompanied by current account improvements and subdued consumption.

To study the relationship between house price movements, housing construction, consumption and international borrowing, we generalize the closed economy asset pricing models developed previously in Adam and Marcet $(2010,2011)$ and Adam Marcet and Nicolini (2010) along three dimensions. First, we consider a setting with two assets, namely a domestically traded risky asset the housing stock - and an internationally traded riskless bond. Second, we newly incorporate a borrowing constraint that limits household leverage and the overall amount of borrowing, following Kiyotaki and Moore (1997). Third, we consider a production economy with endogenous asset supply by explicitly incorporating a construction sector. Despite these extensions our model is relatively parsimonious.

The quantitative success of the model crucially rests on the assumption that we allow for households that are uncertain about how house prices relate to economic fundamentals. Our households are thus at par with academic economists who appear to be equally uncertain about the right model governing asset prices. We incorporate this feature by putting to work the concept of 'internal rationality', as developed previously in Adam and Marcet (2010, 2011). Internally rational investors are utility maximizers in the standard sense and entertain fully specified and dynamically consistent beliefs about all payoff-relevant variables that are external to them (including competitive market prices). Internally rational agents, however, do not fully understand how market prices are formed, so that their subjective probability distribution about prices may not be exactly equal to the true equilibrium distribution. Agents nevertheless have a very good understanding of how to predict prices. First, their beliefs about prices are near-rational in the sense that they are assumed to be close to the rational expectations equilibrium (REE) beliefs typically attributed to agents in the literature. Second, the model that agents entertain about price behavior is validated by actual data, in the sense that it would be accepted by a standard testing procedure using actual data. Third, agents' house price model is validated by the outcome of the asset pricing model itself, in the sense that it would be rejected by an econometric test only as frequently as a model yielding rational expectations ( $\mathrm{RE})$.

Given agents' subjective uncertainty about price, optimal behavior implies that they update beliefs about house price behavior by applying Bayes' rule to market outcomes. Agents' price beliefs thus become a state variable and (Bayesian) learning gives rise to a dynamic feedback between price beliefs and actual price outcomes. As we show, this generates a considerable amount of additional propagation and can fuel boom and bust dynamics in house prices, i.e., price dynamics that temporarily delink asset prices from their fundamental 
value. This is of interest because the momentum in house price changes that can be observed in the data has proven difficult to explain with the help of rational expectations models, see Glaeser and Gyourko (2006). Therefore, Glaeser et al. (2008) previously suggested that models of learning can help resolving this empirical puzzle.

Learning about price dynamics turns out to be important for explaining the persistent rise and fall in house prices occurring over the years 2001-2008 in the G7. Our model thereby suggests that the strong fall in real interest rates after the year 2000 contributed significantly to the subsequent housing boom in some of the G7 economies. In line with the empirical evidence, however, the model predicts that these movements are not necessarily synchronized across countries. While some G7 countries experienced house price booms (US, UK, Canada, Italy, France), they did so to very different degrees, and other countries (Japan, Germany) even displayed stagnant house prices over this period. The model successfully replicates this heterogeneity because the predicted house price evolution is highly dependent on agents' price beliefs at the time of the interest rate reduction, which in turn depend on the behavior of house prices in the respective economies prior to the fall in the real rate.

Our learning model is also compatible with observed house price expectations. Piazzesi and Schneider (2009) use the Michigan Survey of Consumers to document that the share of agents believing prices to increase further comoves positively with the house price level over the last housing boom. Specifically, the share of optimistic agents reached its peak precisely at the time when house prices peaked. This fact is consistent with the learning we propose and difficult to reconcile with rational expectations.

The paper also suggests important policy lessons. Since the world interest rate is an exogenous parameter in the model, we can study the effects of alternative interest rate scenarios. For the U.S. economy the model predicts that the recent US house price boom would have been largely avoided, and the current account deficit would have been considerably smaller, if interest rates had fallen by less at the beginning of the 2000's. Although such a link between real interest rates and house price booms is frequently discussed in the press ${ }^{1}$, to the best of our knowledge we present the first formal model in which a sizable and persistent house price boom can arise from a persistent reduction in the level of real interest rates. ${ }^{2}$

The paper is structured as follows. The next section discusses the related literature on house price fluctuations and current account dynamics. Section 3 presents stylized facts we seek to explain about the behavior of house prices, the current account and private consumption in the G7. Section 4 introduces a stylized open economy model, derives the household optimality conditions and the equations determining the equilibrium outcomes for a general set of subjective

\footnotetext{
${ }^{1}$ E.g., The Economist (August 23, 2007): 'Does America need a recession?', Economic Focus.

${ }^{2}$ Himmelberg et al. (2005) show that with low real interest rates a further reduction in rates can give rise to a large house price increase under rational expectations. It fails, however, to give rise to a persistent sequence of house price increases.
} 
price beliefs. In section 5 we show that the model has difficulties in replicating salient features of the data under rational expectations (RE). Section 6 introduces subjective price beliefs that are close to the REE beliefs (in distribution) and learning about house price behavior. In section 7 we show how the learning model can qualitatively account for the observed dynamics in house prices, current accounts and consumption in the G7. Sections 8 and 9 then explore the quantitative model performance. Finally, section 10 shows that learning agents who are confronted with the model generated house price outcomes would reject their model of house price behavior approximately only as often as a model yielding rational expectations. A conclusion briefly summarizes.

\section{Related Literature}

Relatively few papers study house price dynamics within dynamic equilibrium models before the recent recession. Important exceptions are Iacoviello (2005), who develops a monetary business cycle model with housing and collateral constraints, and Lustig and van Nieuwerburgh (2005) who study the role of house prices and housing collateral for the pricing of stocks.

Some recent papers use models of learning to explain observed house price data. Burnside, Eichenbaum and Rebelo (2011), for example, present a model in which a temporary house price boom emerges from infectious optimism that eventually dissipates once investors become increasingly certain about fundamentals. Laibson and Mollerstrom (2010) present a model in which aggregate wealth fluctuates because agents learn about the expected future productivity of capital goods. Positive news about future productivity is shown to generate an increase in asset prices, a consumption boom and a current account deficit. The small volatility of macroeconomic fundamentals, however, poses problem for such news driven explanations of asset price fluctuations.

Other papers also account for some of the empirical features that we describe. Matsuyama (1990) provides a theoretical analysis of the income effect of government spending, housing subsidies and sector-specific productivity change on residential investment and the current account. He shows that anticipated government spending shocks lead to a decline in house prices and residential investment, but that the effect on the current account depends on whether housing and nondurable consumption are substitutes or complements. Punzi (2006) evaluates the quantitative impact of the housing market on the current account using a two-sector, two-country DSGE model with heterogenous agents and a housing collateral constraint. In her setup, housing preference shocks generate a negative correlation between house prices and the current account. Gete (2010) seeks to explain current account and housing price dynamics through cross-country heterogeneity in the evolution of housing demand. If the desire to smooth consumption across housing services and nondurable consumption goods is strong or if households' preferences feature low intra-temporal substitution elasticity, then an increase in housing demand can give rise to a house price increase and a current account deficit. 


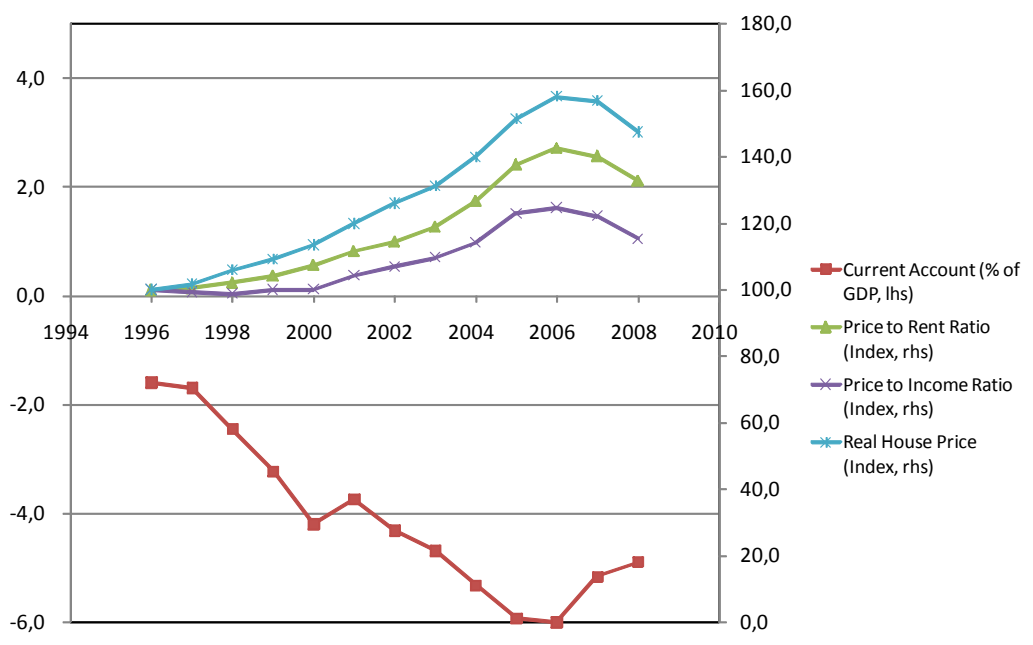

Figure 1: United State: House Price Measures and the Current Account

\section{Stylized Facts}

\subsection{U.S. House Prices and the Current Account 1996-2008}

A variety of house price measures indicate that house prices in the United States increased considerably over the years 1996-2006. Figure 1 depicts indices of the real house price (RHP), the price-to-income (PIR) ratio, and the price-to-rent $(\mathrm{PRR})$ ratio normalizing indices to a value of 100 in the year $1996 .{ }^{3}$ Prices increased - depending on the preferred house price measure - between $24 \%$ and $58 \%$ in the subsequent 10 years. While house prices started increasing well before the year 2000, all house price measures indicate that over $70 \%$ of the total increase takes place after the year 2000.

Figure 1 also depicts the U.S. current account deficit (in \% of GDP). ${ }^{4}$ The current account and the house price are strongly negatively associated over time, with the deficit widening considerably throughout the period 1996 - 2006, except for a slight and temporary improvement in the recession year 2001. Once house prices started to revert direction in the years 2007 and 2008, however, the U.S. current account deficit also started to narrow, a development that accelerated in the year 2009 (see the current account data in table 1 below).

Table 1 below reports the annual change in the value of the U.S. housing stock (at market prices), together with the size of the current account deficit. ${ }^{5}$

\footnotetext{
${ }^{3}$ The data is taken from the OECD Economic Outlook No. 87, 2010, Annex Tables 59 and 60. The real house price index is the nominal house price index deflated by CPI price index.

${ }^{4}$ The data is from the OECD Economic Outlook No. 87, 2010, Annex Table 51.

${ }^{5}$ The change in housing value is computed using the Federal Reserve Board Flow of Funds Statistics, Table B.100, Release 2010-12-9. The current account numbers are taken from NIPA
} 
The bottom row in the table reveals that in the period 1996-2005, any $1 \$$ increase in the value of the U.S. housing stock was on average associated with a $0.26 \$$ increase in international borrowing in the form of a current account deficit. This relationship is remarkably stable over these years (the standard deviation is just 0.04) but changes after the year 2006 when current account deficits improve only mildly, despite the domestic housing value either increasing less strongly (in 2006) or decreasing substantially (after 2007).

\begin{tabular}{|c|c|c|c|c|c|c|c|c|c|c|c|c|c|c|}
\hline Year: & 96 & 97 & 98 & 99 & 00 & 01 & 02 & 03 & 04 & 05 & 06 & 07 & 08 & 09 \\
\hline Value change & & & & & & & & & & & & & & \\
\hline $\begin{array}{l}\text { U.S. house stock } \\
\text { (vs prev. year, } \\
\text { trn dollars) }\end{array}$ & +0.4 & +0.5 & +0.9 & +1.0 & +1.7 & +1.4 & +1.3 & +1.7 & +2.6 & +3.5 & +1.0 & -1.7 & -3.8 & -0.8 \\
\hline $\begin{array}{l}\text { U.S. CA deficit } \\
\text { (bn dollars) }\end{array}$ & 114 & 129 & 205 & 292 & 410 & 392 & 452 & 516 & 625 & 741 & 798 & 717 & 670 & 380 \\
\hline $\begin{array}{l}\text { CA deficit/ch. } \\
\text { in house value }\end{array}$ & 0.27 & 0.24 & 0.22 & 0.28 & 0.25 & 0.28 & 0.34 & 0.30 & 0.23 & 0.21 & 0.84 & -0.41 & -0.18 & -0.45 \\
\hline
\end{tabular}

Table 1: U.S. Housing Value Appreciation and the Current Account

\subsection{U.S.: Real Rates, Consumption, and Construction}

The house price and current account developments in the U.S. highlighted in the previous section were accompanied by a number of other broad macroeconomic trends that we now describe. We thereby focus on three variables, namely the behavior of real interest rates, private consumption and construction activity

The acceleration of the U.S. house price increase and the widening of current account deficits after the years 2000/2001 coincided with a considerable fall in ex-ante real interest rates. Figure 2 illustrates this fact by depicting the one year adjustable mortgage rate subtracting from it the median expected 1 year ahead CPI inflation rate from the survey of professional forecasters. ${ }^{6}$ The figure shows that ex-ante real interest rates considerably dropped around the beginning of the year 2001 and stayed low for an extended period of time, before rising again around the year 2006. Overall, real interest rates display considerably less persistence than real house prices. While real interest rates completed a full cycle over the years 1996-2006, house prices steadily increased throughout this period. It thus appears far from immediate to establish a close link between house prices and real interest rates in the data.

tables, as downloaded through the FRB St. Louis FRED database.

${ }^{6}$ The mortgage rate is the '1-year adjustable rate mortgage average in the United States' from Freddie Mac (SeriesID: MORTGAGE1US). 


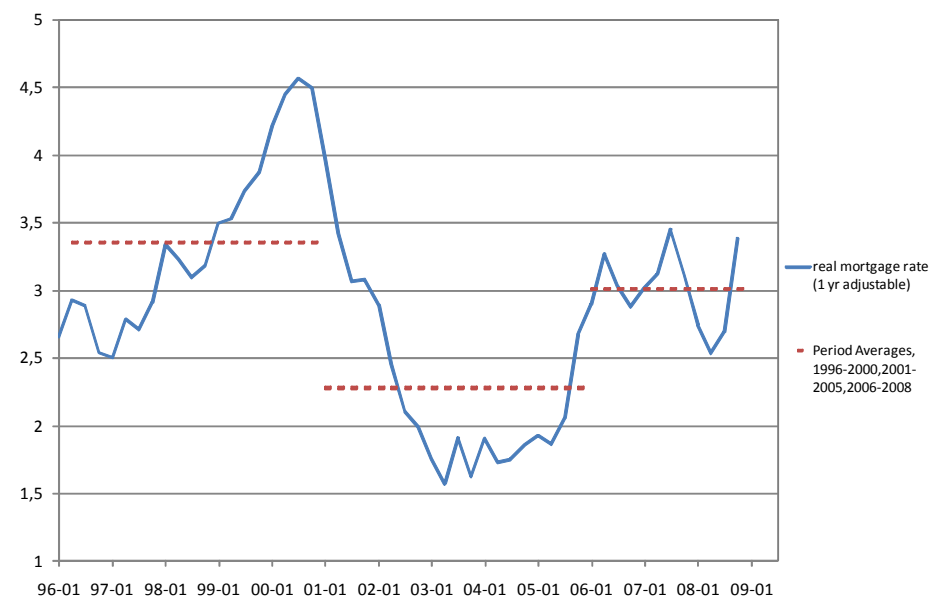

Figure 2: United States: Ex-Ante Real Mortgage Rate

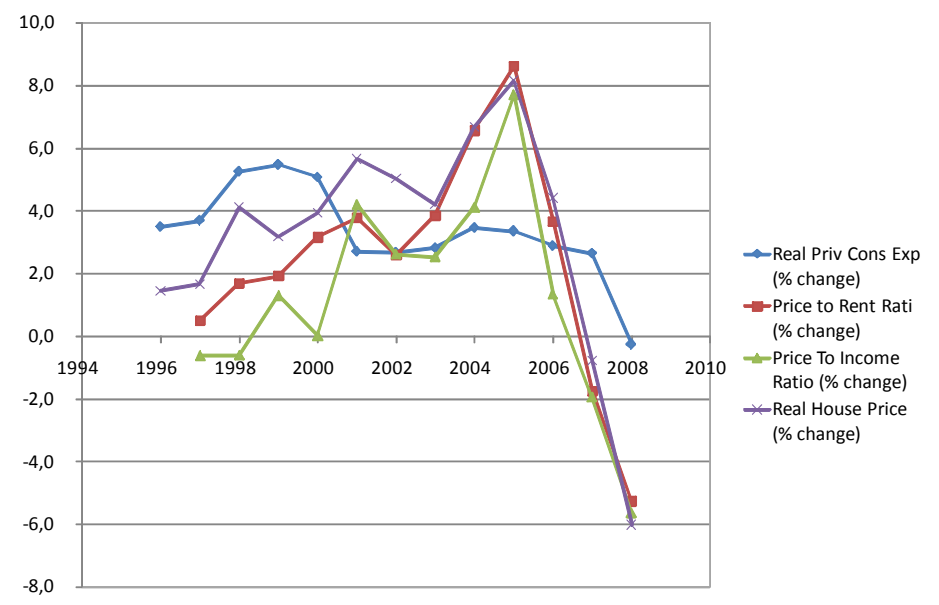

Figure 3: United States: House Price Changes and Consumption Growth 


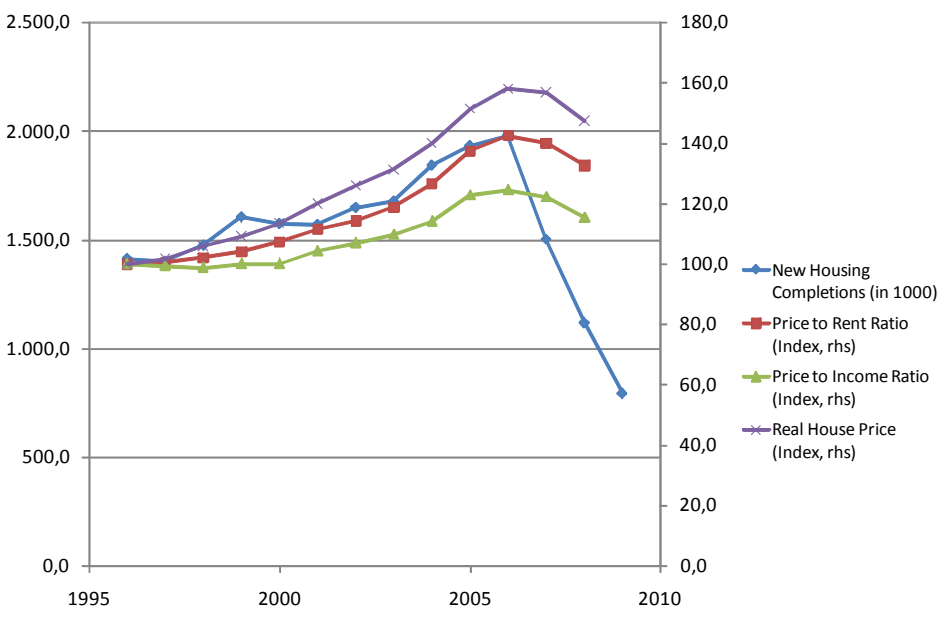

Figure 4: United States: House Prices and New Housing Completions

To capture the interest rate evolution in a stylized way, we consider three subperiods: a period with relatively high real rates over the years 1996-2000, a period with relatively low real rates over the years 2001-2005, and a period of moderately high rates in the years 2006-2008. The horizontal lines in figure 2 indicate the average interest rate for each of these subperiods.

Figure 3 depicts real private consumption growth together with various measures of house price growth. ${ }^{7}$ Private consumption expanded over the years 1996-2006 by more than $3 \%$ each year, but came down after house prices reverted direction in 2007 and 2008. As has been documented before, there is thus a positive association between house price and consumption growth in the data.

The number of new houses built in the U.S. also strongly expanded over the period 1996-2006. Figure 4 reports the number of new housing units completed in the U.S. together with various house price measures. ${ }^{8}$ The figure shows that the level of house prices and the number of housing completions are strongly positively correlated.

\subsection{Cross-Sectional Evidence from G7 Economies}

The facts documented for the U.S. Economy in the previous section, appear in similar form in the cross section of G7 economies. ${ }^{9}$

\footnotetext{
${ }^{7}$ The real private consumption growth data is from the OECD Economic Outlook No.87, 2010, Annex Table 3. The house price series employ the same data as used for figure 1.

${ }^{8}$ The housing units data is from U.S. Census Bureau, using the series 'new privately owned housing units completed'. The house price series are the same as the ones shown in figure 1.

${ }^{9}$ Data limitations prevent us from discussing the behavior of new housing construction or the relationship between value changes of the housing stock and the current account for all
} 


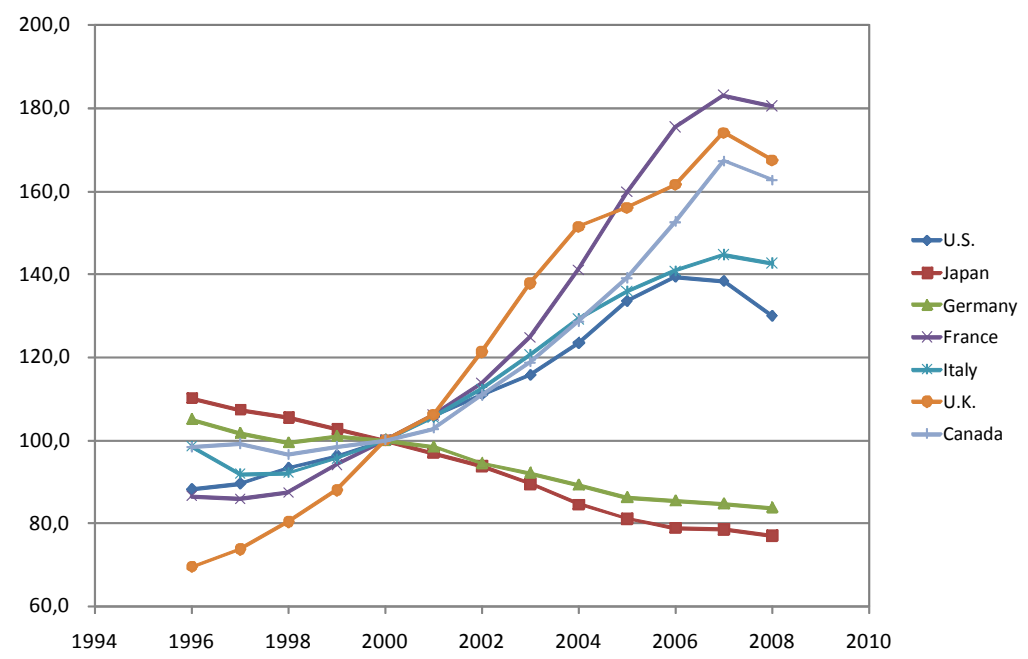

Figure 5: Real House Prices in the G7 (Indices, Normalized to 100 in Year 2000)

Table 2 below shows that over the period 2001-2007 house price increases and current account surpluses are negatively correlated in the cross-section of G7 countries. ${ }^{10}$ Countries with larger house price booms thus tended to have also larger current account deficits. This holds independently of the considered house price measure (RHP, PIR, PRR). Furthermore, house price increases are strongly positively correlated with real private consumption growth over the same period, showing that countries with larger house price booms also tended to have larger consumption booms. Finally, as shown in table 3 , the house price reversals in 2007-2008 are similarly strongly negatively correlated with changes in the current account surplus. These cross-sectional relationships are consistent with the correlation over time that can observed for U.S. data.

Although the G7 evidence confirms the comovements between house price, current account and consumption dynamics documented for the U.S., there exists a considerable amount of cross-sectional heterogeneity across the G7 economies. Figure 5 illustrates this fact by depicting the real house price indices for the G7 economies, normalizing the house price indices to 100 for the year $2000 .{ }^{11}$ It is clear that house prices show high volatility and high persistence in all countries. Table 4 documents the latter fact by reporting the average serial correlation of housing prices over time across the G7 countries.

Importantly, however, the large low frequency movements in house prices

G7 countries.

${ }^{10}$ Aizenman and Jinjarak (2009) also provide evidence on the strong positive association between current account deficits and the appreciation of real estate prices across a number of countries.

${ }^{11}$ The figure looks very similar when depicting instead the the price-to-rent ratio or the price-to-income ratio. 
are not synchronized across countries. While four countries experienced sustained and even larger house price increases after 2000 than the U.S., Japan and Germany witnessed real price decreases.

\begin{tabular}{|c|c|c|}
\hline $\begin{array}{l}\text { House Price } \\
\text { Change 2001-07 }\end{array}$ & $\begin{array}{l}\text { Current Account } \\
\text { Surplus } \\
\text { (2001-07, cum. sum } \\
\text { in \% of GDP) } \\
\end{array}$ & $\begin{array}{c}\text { Real Priv. Cons. } \\
\text { Increase } \\
(2001-2007, \\
\text { cum. sum in \%) } \\
\end{array}$ \\
\hline Real house price & -0.55 & 0.72 \\
\hline Price-rent ratio & -0.42 & 0.75 \\
\hline Price-income ratio & -0.52 & 0.61 \\
\hline
\end{tabular}

Table 2: Cross-Sectional Correlations in the G7

\begin{tabular}{lc} 
House Price Change 2007-2008 & $\begin{array}{c}\text { Change in Current Account Surplus } \\
\mathbf{2 0 0 8} \text { vs. 2007 } \\
\text { (in \% of GDP) }\end{array}$ \\
\hline Real house & -0.75 \\
Price-rent ratio & -0.90 \\
Price-income ratio & -0.83 \\
\hline
\end{tabular}

Table 3: Cross-Sectional Correlations in the G7 


\section{House Prices Measure}

$\begin{array}{lc}\text { real house prices } & 0.98 \\ \text { price-to-rent ratio } & 0.97 \\ \text { price-to-income } & 0.97\end{array}$

Table 4: Autocorrelation of G7 House Prices

\section{An Open Economy Model with Housing}

This section presents a parsimonious open economy model with endogenous housing supply in which households can internationally borrow for consumption and investment purposes. Household borrowing is thereby subject to a collateral-based borrowing constraint, as in Kiyotaki and Moore (1997).

Preferences and Beliefs. We consider an economy populated by a unit mass of utility maximizing households. Households are identical in terms of preferences and beliefs - a fact that is not known to agents ${ }^{12}$ - with the representative household maximizing

$$
E_{0}^{\mathcal{P}} \sum_{t=0}^{\infty} \delta^{t}\left(\xi_{t} h_{t}+c_{t}\right)
$$

where $c_{t} \geq 0$ denotes consumption of goods, $h_{t} \geq 0$ consumption of housing services, $\delta \in(0,1)$ the time discount factor, and $\xi_{t}>0$ a housing preference shock. We assume that the preference shock evolves according to

$$
\ln \xi_{t}=\ln \xi_{t-1}+\ln \varepsilon_{t}
$$

with $\varepsilon_{t}$ being an $i i d$ innovation satisfying $E\left[\ln \varepsilon_{t}\right]=0$ and $E\left[\left(\ln \varepsilon_{t}\right)^{2}\right]=\sigma_{\varepsilon}^{2}$. The preference shock $\xi_{t}$ captures changes in the population's preferences for housing services relative to consumption. As we argue below, the assumed unit root specification is broadly consistent with the available data.

The household's expectation in (1) is computed using a (potentially subjective) probability measure $\mathcal{P}$, which is defined over the space of payoff-relevant

\footnotetext{
${ }^{12}$ As explained in Adam and Marcet (2011), common knowledge of agents' preferences and beliefs might place additional restrictions on the house price beliefs that rational agents can entertain, so we need to assume absence of common knowledge.
} 
outcomes $\Omega$. The measure $\mathcal{P}$ assigns probabilities to all subsets of $\Omega$ in a sigmaalgebra $\mathcal{B}$, so that agents entertain a standard probability space $(\mathcal{P}, \mathcal{B}, \Omega)$. Importantly, the set $\Omega$ includes all sequences of payoff-relevant variables that agents take as given. This includes fundamental shocks, but also competitive market prices. Agents' choices in a given period $t$ are then functions of the realization of these payoff-relevant variables up to $t$. While the measure $\mathcal{P}$ itself is timeinvariant, i.e., dynamically consistent, it will often imply that rational agents are learning about the house price process. This is the case, for example, if $\mathcal{P}$ is generated by a model that agents entertain about the stochastic process of house prices and by some prior beliefs about unknown parameters describing this process. Further details about the underlying probability space are given in section 4.1 below.

Budget Constraint and Collateral Constraint. We let $H_{t} \geq 0$ denote the stock of houses owned by the household in period $t$. The housing stock yields housing services $h_{t}$ according to

$$
h_{t}=G\left(H_{t}\right)
$$

for some twice continuously differentiable and (weakly) concave function $G(\cdot)$ satisfying the conditions $\lim _{H \rightarrow 0} G^{\prime}(H)=\infty$ and $\lim _{H \rightarrow \bar{H}} G^{\prime}(H)=-\infty$ for some $\bar{H} \leq \infty$. We impose this latter condition for technical convenience: it insures the existence of an optimal house holding plan for all beliefs about house prices satisfying the restriction that house prices cannot become negative. The above assumptions imply that there is a bliss point $H^{B}$ such that $G^{\prime}\left(H^{B}\right)=0$; with the additional assumption that this bliss point is unique we have $G^{\prime}(H) \geq 0$ for $H<H^{B}$ and $G^{\prime}(H) \leq 0$ for $H>H^{B}$. For reasons that will become apparent below, the housing stock may exceed this bliss point in equilibrium.

Using the consumption good as numeraire and letting $q_{t}$ denote the price of houses, the agent's flow budget constraint is

$$
c_{t}+\left(H_{t}-(1-d) H_{t-1}\right) q_{t}+R b_{t-1}+k_{t}=y_{t}+b_{t}+\pi_{t}+k_{t-1} p_{t}
$$

where $y_{t} \geq 0$ denotes an exogenous income process, $b_{t}$ the household's new loans, $R$ the gross real interest rate on maturing loans $b_{t-1}, d \in[0,1)$ the rate at which the housing stock depreciates, $\pi_{t}$ profits from the ownership of (housing development) firms, and $k_{t} \geq 0$ capital sold to competitive housing developers who use this capital as an input for the production of new houses. This capital stock fully depreciates in one period. To capture time lags in housing production and for simplicity we assume that the price $p_{t}$ remunerating $k_{t-1}$ is a competitive forward price that is fixed in period $t-1$.

For notational simplicity we do not introduce a competitive market for housing services $h_{t}$. While the analysis would remain unchanged with such a market, it would imply that the competitive market for housing services is given by $\xi_{t}$. For this reason we interpret $\xi_{t}$ as the rental price for housing in the remaining part of the paper. And to show that our unit root assumption for $\log \xi_{t}$ is indeed reasonable, table 5 below reports the Dickey-Fuller test statistics for a unit root 
model with drift based on the log of the rental rate for housing in the respective countries. ${ }^{13}$ For the considered sample, the $10 \%$ critical value for this statistic is -2.614 , which is far from any of the reported test statistics. This suggests that our stochastic specification for $\xi_{t}$ is indeed reasonable.

\begin{tabular}{ccccccc}
\hline & US & JAP & GER & FR & UK & CAN \\
$t$-statistic & -0.921 & -0.848 & -0.383 & 0.131 & 0.696 & -0.162 \\
\hline
\end{tabular}

Table 5: Dickey-Fuller Test for Assumed $\xi_{t}$ Process

We assume that consumers' borrowing is subject to a collateral constraint of the form

$$
b_{t} \leq \theta \frac{E_{t}^{\mathcal{P}} q_{t+1}}{R} H_{t}
$$

as in Kiyotaki and Moore (1997). The parameter $\theta \in[0,1-d]$ captures the share of houses owned by the household today that can serve as collateral to lenders, this parameter is assumed fixed. A value of $\theta<1$ thereby incorporates the effects of physical depreciation of houses, as well as the possibility that seizing the collateral in case of default is costly for lenders.

The borrowing constraint (5) will be key to understand the model-implied relation between house prices and current account dynamics. In a situation where actual and expected prices tend to grow, the borrowing constraint will be relatively loose. Agents can thus increase international borrowing when house prices grow, thereby establishing a connection between house price booms and current account deficits. ${ }^{14}$

We assume that there is a sufficiently wealthy risk neutral international lender which holds the same beliefs $\mathcal{P}$ as domestic agents. The international lender has a time discount rate $R^{-1}$ which we assume to satisfy $R^{-1} \in(\delta, 1)$. The latter implies that the international lender is more patient than domestic households. In addition to simplifying the analysis, it captures the presence of China and other emerging economies as large and patient international lenders in the global economy. We also assume that the market for collateralized loans is internationally fully integrated. With these assumptions, the world equilibrium interest rate for collateralized loans is given by $R . .^{15}$

\footnotetext{
${ }^{13}$ The data is from the OECD, using a sample spanning the years 1970-2008. Italy is excluded because the rental data is only available from 1996 onwards. The regression used in the Dickey Fuller test is based on the model $\log \xi_{t}=\alpha+\rho \log \xi_{t-1}+\varepsilon_{t}$, and the null hypothesis $\alpha=0, \rho=1$ is tested against the alternative $\alpha \neq 0$ and $\rho<1$. The reported statistic is the estimate for $\rho-1$ divided by its estimated standard deviation.

${ }^{14} \mathrm{Using}$ current houses prices instead of expected future prices in the borrowing constraint (5) would make virtually no difference for our purposes, as actual and expected prices tend to move together in the learning model we consider.

${ }^{15} \mathrm{It}$ is easy to rule out interest rates below $R$ as then domestic and foreign agents both wish to borrow, implying that the loan market cannot clear. For interest rates above $R$
} 
Housing Supply. We now turn to the determinants of housing supply. There exists a competitive housing development sector consisting of a unit mass of housing development firms. The representative firm operates a decreasing returns to scale technology for constructing new houses. The amount of new housing produced at $t$ is given by

$$
(\alpha \delta)^{-1} k_{t-1}^{\alpha}
$$

with $k_{t-1} \geq 0$ denoting the amount of development capital used by housing developers and $\alpha \in(0,1)$. To capture time lags in housing construction we assume that firms choose the level of input $k_{t-1}$ in period $t-1$, i.e., one period in advance.

Firms in the housing sector are owned by the consumer in the small open economy, who receive profits as lump sum transfers. Since firms do not have a true intertemporal maximization problem (there is no state variable in the firms' problem), we can assume that they maximize expected profits from housing construction by choosing ${ }^{16}$

$$
\max _{k_{t-1} \geq 0} E_{t-1}^{\mathcal{P}}\left(\frac{1}{\alpha \delta} k_{t-1}^{\alpha} q_{t}-p_{t} k_{t-1}\right)
$$

where $p_{t}$ is the price of period $t$ inputs purchased from households in period $t-1$ in a competitive forward market. The profit-maximizing input choice is given by

$$
k_{t-1}^{*}=\left(\frac{E_{t-1}^{\mathcal{P}} q_{t}}{\delta p_{t}}\right)^{\frac{1}{1-\alpha}}
$$

and determines a supply function for new houses of the form

$$
S\left(E_{t-1}^{\mathcal{P}} q_{t}, p_{t}\right)=\frac{1}{\alpha \delta}\left(\frac{E_{t-1}^{\mathcal{P}} q_{t}}{\delta p_{t}}\right)^{\frac{\alpha}{1-\alpha}}
$$

with $\frac{\alpha}{1-\alpha}$ denoting the elasticity of housing supply with respect to the expected selling price $E_{t-1}^{P} q_{t}$. The housing stock then evolves according to

$$
H_{t}=(1-d) H_{t-1}+S\left(E_{t-1}^{\mathcal{P}} q_{t}, p_{t}\right)
$$

and developers' realized profits in period $t$ are given by

$$
\pi_{t}=\frac{1}{\alpha \delta}\left(\frac{E_{t-1}^{P} q_{t}}{\delta p_{t}}\right)^{\frac{\alpha}{1-\alpha}} q_{t}-p_{t}\left(\frac{E_{t-1}^{\mathcal{P}} q_{t}}{\delta p_{t}}\right)^{\frac{1}{1-\alpha}}
$$

the foreign lender wishes to borrow up to its borrowing constraint. If the foreign agent is sufficiently wealthy, this would lead to a violation of the non-negativity constraint on domestic consumption. It thus has to be the case that the interest rate equals $R$. Provided the foreign lender is sufficiently wealthy, lending to domestic agents will imply non-negative consumption for the foreign lender.

${ }^{16}$ As should become from section 4.1 below, one should use a slightly different belief system for firms than used for consumers because profits are a choice variable for firms, while consumers take profits as given. Since this does not affect the expectations showing up in the subsequent firm optimality conditions, we ignore this issue in the text. 


\subsection{The Underlying Probability Space}

We now describe details of the underlying probability space $(\mathcal{P}, \mathcal{B}, \Omega)$. The probability space is entirely standard from viewpoint of probability theory, but will be extended (or more general) when compared to the approach taken in the RE literature. Specifically, we define the state space of outcomes as

$$
\Omega \equiv \Omega_{p} \times \Omega_{q} \times \Omega_{\xi} \times \Omega_{y} \times \Omega_{\pi}
$$

where $\Omega_{X}=\prod_{t=0}^{\infty} R_{+}$is the space of possible infinite sequences for the variable $X \in\{p, q, \xi, y, \pi\}$. We thus do not restrict attention to the history of 'fundamental' or exogenous variables $(\xi, y)$, instead include all sequences of payoff-relevant variables that agents take as given in their decision problem. This includes prices and profits, in addition to the 'fundamental' variables.

The set of all possible histories up to period $t$ for some variable $X$ is then denoted by $\Omega_{X}^{t}$, and its typical element $X^{t} \in \Omega_{X}^{t}$, except for $p$ where $\Omega_{p}^{t}$ denotes histories up to $t+1$. Furthermore, we let $\Omega^{t}=\Omega_{p}^{t} \times \Omega_{q}^{t} \times \Omega_{\xi}^{t} \times \Omega_{y}^{t} \times \Omega_{\pi}^{t}$ denote the set of histories of all exogenous variables up to period $t$, and $\omega^{t} \in \Omega^{t}$ its typical element. $\mathcal{B}$ is the sigma-algebra of all Borel subsets of $\Omega$ and $\mathcal{P}$ a measure on this sigma-algebra. The probability space $(\mathcal{P}, \mathcal{B}, \Omega)$ is assumed common to all agents, including firms, domestic consumers and foreign agents.

The previous setup implies that agents can condition their decisions on the history of all observed realizations, i.e., consumers choose for each $t$

$$
\left(c_{t}, h_{t}, H_{t}, b_{t}, k_{t}\right): \Omega^{t} \rightarrow R^{5} .
$$

Conditioning on all observed realizations will be optimal whenever agents do not know how a given history of fundamentals $(y, \xi)^{t}$ maps into outcomes for prices and profits. This differs from a RE setting where prices $\left(p_{t}, q_{t}\right)$ and profits $\pi_{t}$ are known functions of the history of fundamentals, implying that conditioning also on the history of prices and profits would simply be redundant.

Agents express their uncertainty about the joint distribution of prices and fundamentals using the probability measure $\mathcal{P}$. In the spirit of studying small deviations from rational expectations, we will specify below a probability measure $\mathcal{P}$ that is close - but not exactly equal - to the rational expectations equilibrium beliefs.

\subsection{Household Optimality Conditions}

We now derive the conditions characterizing optimal household behavior. We thereby proceed by assuming that a maximum for the household problem exists. $^{17}$ First order conditions are then necessary and sufficient for household optimality because the objective function is concave and the constraints are linear in the households' choices.

\footnotetext{
${ }^{17}$ Existence of a maximum can be insured, for example, by imposing that the utility from consumption $\left(c_{t}\right)$ is bounded at some very high level. See Appendix A.1 in Adam and Marcet (2011) for how this can be achieved in a related model.
} 
Households maximize the objective (1) subject to the constraints (3), (4) and (5). Taking explicitly into account the non-negativity constraints for $c_{t}$ and $k_{t}$, the Lagrangian of the household problem is given by

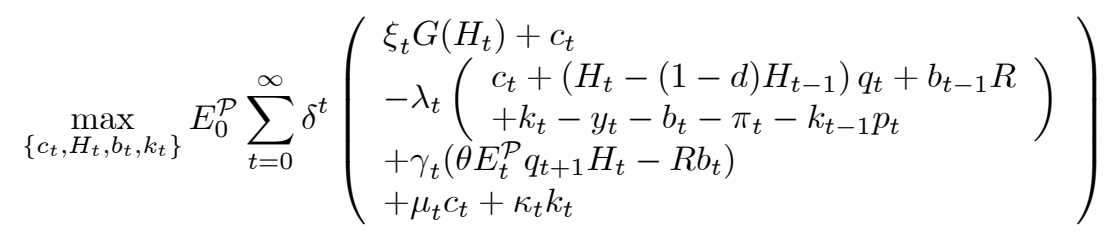

where $H_{-1}, k_{-1}$ and $b_{-1}$ are given initial conditions and the prices $\left\{q_{t}, p_{t}\right\}, R$ are given.

The household's first order conditions (FOCs) are

$$
\begin{aligned}
c_{t}: & \lambda_{t}=1+\mu_{t} \text { with } \mu_{t} \geq 0 \& c_{t} \mu_{t}=0 \\
H_{t}: & \xi_{t} G^{\prime}\left(H_{t}\right)-\lambda_{t} q_{t}+\delta(1-d) E_{t}^{\mathcal{P}} \lambda_{t+1} q_{t+1}+\gamma_{t} \theta E_{t}^{\mathcal{P}} q_{t+1}=0 \\
b_{t}: & \lambda_{t}=\delta R E_{t}^{\mathcal{P}} \lambda_{t+1}+\gamma_{t} R \text { with } \gamma_{t} \geq 0 \\
& \&\left(\theta E_{t}^{\mathcal{P}} q_{t+1} H_{t}-R b_{t}\right) \gamma_{t}=0 \\
k_{t} \quad: & \lambda_{t}=\delta p_{t+1} E_{t}^{\mathcal{P}} \lambda_{t+1}+\kappa_{t} \text { with } \kappa_{t} \geq 0 \& k_{t} \kappa_{t}=0
\end{aligned}
$$

for all $t \geq 0$. Equation (10) implies that $\lambda_{t} \geq 1$.

We now describe the evolution of the equilibrium variables. In the main text we thereby focus on the case where the non-negativity constraint for $c_{t}$ is not binding for all $t \leq T+1$, where $T$ denotes the sample size. ${ }^{18}$ Since $R<\frac{1}{\delta}$ the optimal solution then implies that the consumer will optimally borrow as much as possible, so that the collateral constraint is binding in each period $t \leq T$. Then, provided the fluctuations in house prices and house price expectations are not too large, the non-negativity constraint for consumption will indeed not be violated. ${ }^{19}$ In this case, $\mu_{t}=0$ for all $t=0, \ldots, T$ so that the FOC (10) is satisfied for $\lambda_{t}=1$ and the FOC (12) holds for

$$
\gamma_{t}=\frac{1}{R}-\delta>0
$$

for all $t=0, \ldots, T$. Using these results and equation (11) one obtains

$$
q_{t}=\rho E_{t}^{\mathcal{P}} q_{t+1}+\xi_{t} G^{\prime}\left(H_{t}\right)
$$

where

$$
\rho \equiv \delta(1-d-\theta)+\frac{\theta}{R}<1
$$

Given $q_{t}$ and $E_{t}^{\mathcal{P}} q_{t+1}$, equation (14) determines the optimal amount of houses demanded by the household. Since $G^{\prime}(\cdot)$ continuously varies between $+\infty$ and

\footnotetext{
${ }^{18} \mathrm{~A}$ full characterization of optimal outcomes is found in appendix A. Since zero consumption does not accord well with the data, this approach appears justified.

${ }^{19}$ Although a large drop in the expected future house price may imply that loans have to be repaid to an extend that consumption would have to become negative, we consider values of the shocks for which this does not occur for the $T+1$ periods in our simulations.
} 
$-\infty$, this equation always has a solution for the optimal housing stock $H_{t}>0$, for any given pair $\left(q_{t}, E_{t}^{\mathcal{P}} q_{t+1}\right)$.

Importantly, for $q_{t}<\rho E_{t}^{\mathcal{P}} q_{t+1}$, equation (14) implies $G^{\prime}\left(H_{t}\right)<0$, so that housing demand exceeds the bliss point level $H^{B}$. If houses are expected to appreciate sufficiently strongly, it can become individually optimal to purchase housing above the bliss point since housing investment generates capital gains and relaxes the household's borrowing constraint.

When the collateral constraint is binding in the first $T+1$ periods, the optimal level of borrowing follows from the binding collateral constraint and is given by

$$
b_{t} R=\theta E_{t}^{\mathcal{P}} q_{t+1} H_{t}
$$

The capital offered by the consumer to housing developers is only restricted to satisfy

$$
\left(1-\delta p_{t+1}\right) k_{t}=0
$$

so that either $p_{t}=\delta^{-1}$ or $k_{t}=0$. If the non-negativity constraint on $k$ is non-binding, the agent is indifferent between consuming today and increasing by one unit the capital sold to firms in exchange for $\delta^{-1}$ units of consumption tomorrow. Since firms' production function implies that firms always have a positive demand for $k$, market clearing occurs at

$$
p_{t}=\delta^{-1}
$$

with $k_{t}$ being determined by firms' demand function.

Finally, consumption can be obtained residually from the flow budget

$$
c_{t}=y_{t}+b_{t}+\pi_{t}-\left(H_{t}-(1-d) H_{t-1}\right) q_{t}-b_{t-1} R-k_{t}+k_{t-1} \delta^{-1}
$$

where we imposed (17).

\subsection{Equilibrium Dynamics for General Beliefs $\mathcal{P}$}

For arbitrary and given beliefs $\mathcal{P}$, the equilibrium evolution of the house price $q_{t}$ and the housing stock $H_{t}$ must satisfy equations (14) and (7), rewritten here as

$$
\begin{gathered}
q_{t}=\rho E_{t}^{\mathcal{P}} q_{t+1}+\xi_{t} G^{\prime}\left(H_{t}\right) \\
H_{t+1}=(1-d) H_{t}+S\left(E_{t}^{\mathcal{P}} q_{t+1}, \delta^{-1}\right)
\end{gathered}
$$

These equations can be solved for the process $\left\{q_{t}, H_{t}\right\}_{t=0}^{\infty}$. Borrowing then follows from equation (16), housing supply from (6), profits from (8) and equilibrium consumption from (18).

\section{Rational Expectations Equilibrium (REE)}

We now assume rational expectations $\left(E_{t}^{\mathcal{P}}[\cdot]=E_{t}[\cdot]\right)$ and determine the rational expectations equilibrium (REE) for the case where the non-negativity constraint 
on consumption is never binding. We first find the deterministic steady state, then analyze the effects of preference and income shocks, and finally discuss the effects of changes in international real interest rates. As will become clear from the discussion below, under RE the model has great difficulties in replicating the observed house price dynamics.

\subsection{Deterministic Steady State}

We start out by determining the deterministic steady state, i.e., the REE in which $\xi_{t}=\xi$ and $y_{t}=y$ for all $t$. Letting variables without time subscripts denote steady outcomes, equations (19) and (20) imply

$$
\begin{aligned}
q^{s s} & =\frac{\xi G^{\prime}\left(H^{s s}\right)}{1-\rho} \\
H^{s s} & =\frac{1}{\alpha \delta d}\left(q^{s s}\right)^{\frac{\alpha}{1-\alpha}}
\end{aligned}
$$

which jointly determine a unique steady state value for $q^{s s}$ and $H^{s s} \cdot{ }^{20}$ Steady state capital, borrowing and consumption are given by

$$
\begin{aligned}
k^{s s} & =\left(q^{s s}\right)^{\frac{1}{1-\alpha}} \\
b^{s s} & =\theta \frac{q^{s s} H^{s s}}{R} \\
c^{s s} & =y+\theta\left(\frac{1}{R}-1\right) q^{s s} H^{s s}-\left(q^{s s}\right)^{\frac{1}{1-\alpha}}
\end{aligned}
$$

\subsection{Stochastic Equilibrium: Linear Approximation}

We now analyze the effects of shocks to housing preferences $\xi_{t}$ and household income $y_{t}$. In the interest of deriving closed form approximate solutions, we first consider solutions to equations (19) and (20) when the function $G(\cdot)$ is linearized around its steady state. This simplifies the analysis because it allows using results previously derived in Adam, Marcet and Nicolini (2010) to describe the model behavior under learning. We consider a concave function $G(\cdot)$ separately below.

Substituting $G^{\prime}\left(H_{t}\right)$ by $G^{\prime}\left(H^{s s}\right)$ in equation (19) implies that the REE house price to rent ratio is (approximately) given by

$$
\frac{q_{t}^{R E}}{\xi_{t}}=\frac{G^{\prime}\left(H^{s s}\right)}{1-\rho}
$$

so that log house price growth evolves according to

$$
\ln \frac{q_{t}^{R E}}{q_{t-1}^{R E}}=\ln 1+\ln \varepsilon_{t}
$$

\footnotetext{
${ }^{20}$ Existence and uniqueness follow from the following considerations. Equation (21) defines $q$ as a continuous and (weakly) decreasing function of $H$ which approaches $+\infty$ as $H \rightarrow 0$ and $-\infty$ as $H \rightarrow \bar{H}$. From (22) we have that $q$ is a strictly increasing function of $H$. As a result there exist a unique intersection.
} 
For the linear approximation we thus have $E_{t} q_{t+1}^{R E}=q_{t}^{R E}$ and $p_{t}=\delta^{-1}$, so that the housing stock approximately evolves according to: ${ }^{21}$

$$
H_{t+1}^{R E}=(1-d) H_{t}^{R E}+\frac{1}{\alpha \delta}\left(q_{t}^{R E}\right)^{\frac{\alpha}{1-\alpha}}
$$

The previous findings show that preference and income shocks both fail to affect the price-to-rent ratio (23) and that the real house price follows a unit root in this approximate REE. With rational expectations, preference and income shocks thus cannot explain the large swings in the price-to-rent ratio and are unlikely to explain the persistent boom and bust patterns in real house prices observed in the data.

\subsection{Stochastic Equilibrium: Linear-Quadratic Approxima- tion}

While the linear approximation considered in the previous section is convenient, assuming linearity of $G(\cdot)$ violates our basic assumptions required to guarantee existence of an equilibrium. We therefore consider a model with a concave $G(\cdot)$ in all subsequent computations, but use the linear approximation from the previous section for intuitive explanations. Appendix B shows that with a linear-quadratic approximation to $G(\cdot)$, the REE dynamics evolve according to

$$
\begin{aligned}
\widehat{q}_{t} & =a^{R E} \widehat{\xi}_{t}+b^{R E} \widehat{H}_{t} \\
\widehat{H}_{t+1} & =c^{R E} \widehat{H}_{t}+d^{R E} \widehat{\xi}_{t}
\end{aligned}
$$

where hatted variables denote deviations from the steady state and $\left(a^{R E}, b^{R E}, c^{R E}, d^{R E}\right)$ are given coefficients satisfying $a^{R E}>0, b^{R E}<0,0<c^{R E}<1$ and $d^{R E}>0$.

Importantly, preference shocks still cannot explain the observed house price dynamics. A positive innovation to the rental price $\xi_{t}$ increases the rental price on impact, but leads to a reduction of the equilibrium price in the subsequent period. ${ }^{22}$ The model will thus have difficulties with generating a persistent increase of the house price. Furthermore, the previous equation imply that the stock of housing and the price-to-rent ratio move in opposite directions. This is intuitive, since the price-to-rent ratio $q_{t} / \xi_{t}$ is equal to the discounted sum of future $G^{\prime}$ and a higher housing stock $H$ reduces the value of $G^{\prime}$. This feature of the rational expectations model is also hard to reconcile with the data, where the price-to-rent ratio and the stock of houses display strong positive comovement.

\subsection{Calibration, House Prices and Real Interest Rates}

We now analyze the effects of unexpected changes in the real interest rate for the REE house price. As equation (23) shows, a reduction in real interest rates generates an increase in the real house price and in the price-to-rent ratio. As

\footnotetext{
${ }^{21}$ The subsequent equation reveals that sufficiently small housing perference shocks will indeed imply that $H_{t}$ stays in the neighborhood of $H$ with high likelihood, as initially assumed.

${ }^{22}$ The former follows from $a^{R E}>0$ and the latter from $d^{R E}>0$ and $b^{R E}<0$.
} 


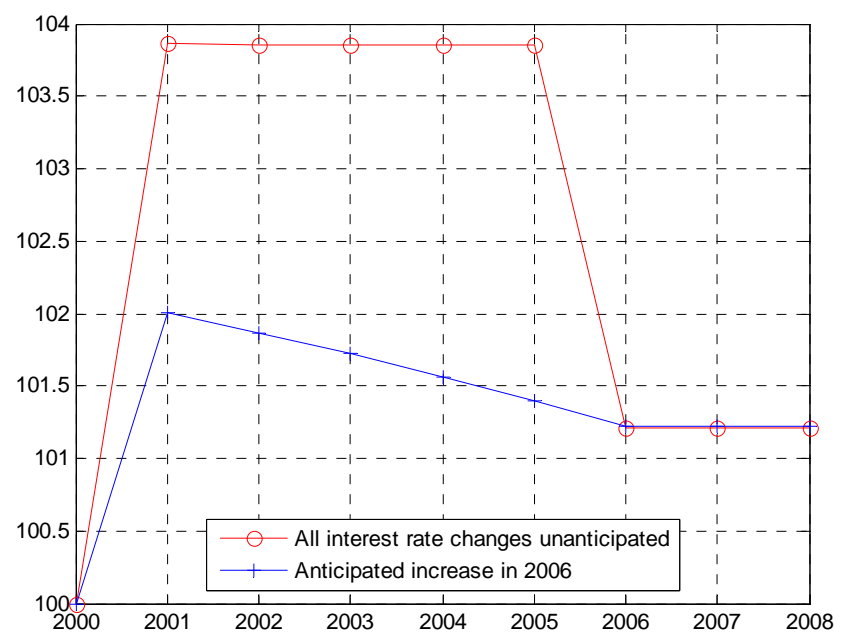

Figure 6: RE Real House Price Dynamics (Stylized Real Rate from Figure 2)

we document below, however, it is unlikely that changes in real interest rates can properly account for the observed house price dynamics.

To analyze the effects of real interest rate changes we assume that the economy starts from a steady state position in the year 2000. We then subject it to the stylized changes in the real interest rate indicated by the dashed line in figure 2. Specifically, we consider a persistent and unexpected decrease in the real rate in the year 2001, followed by an equally unexpected real rate increase in the year 2006. ${ }^{23}$ The effects of anticipated real rate changes will be discussed separately below.

The remaining model parameters are calibrated as follows. We set $\theta=0.26$, which is the 1996-2005 average of the annual value change change in the U.S. housing stock over the current account deficit, see table 1. For the annual discount factor we choose $\delta=0.96$, so that the discount factor is slightly below the real interest rate path that we feed into the model. ${ }^{24}$ We set the annual house depreciation rate equal to $d=3 \%$.

To illustrate the effects of interest rate changes we abstract from uncertainty about preference shocks: we set $\xi_{t}=\xi$ and normalize $\xi G^{\prime}(H)$ such that the initial steady state real house price in the year 2000 (prior to any change in the

\footnotetext{
${ }^{23}$ The initial real interest rate is set equal to the average ex-ante gross real mortgage rate over the periods $1996-2000$, i.e., $R_{96-00}=1.0335$. In the year 2001 we then consider an expected and permanent fall in the real interest rate that lasts for 5 years to a value of $R_{01-05}=1.0228$, which is equal to the average ex-ante U.S. real mortgage rate for this period. Thereafter, we consider an unexpected and permanent upward shift in real rates to $R_{06-08}=1.0301$, which is again taken from the data.

${ }^{24}$ This is required to insure optimality of the binding collateral constraint.
} 
real interest rate) is equal to 100. Finally, for reasons that will become clear later on, we choose a value for the constant second derivative $G^{\prime \prime}$ so that there is a small amount of curvature, i.e., we set $-\frac{G^{\prime \prime} H^{s s}}{G^{\prime}}=0.007$. None of the results shown below proves particularly sensitive to the assumed parameter values.

The resulting REE real house price dynamics from unexpected changes in the interest rate are illustrated by the upper line in figure $6{ }^{25}$ The figure reveals that RE imply that house price changes occur simultaneously with unanticipated changes in real interest rates. ${ }^{26}$ For the U.S. economy, however, one cannot find a close simultaneous association between changes in the real mortgage rates and house prices changes. Mortgage rates, for example, stayed approximately constant between the beginning of 2003 until the end of 2005, see figure 2, while house prices increased strongly over these two years. Likewise, real mortgage rates were roughly constant over the years 2006-2008, while house prices decreased considerably over these years. Due to this close association with interest rates, house prices under RE do not exhibit the persistence that can be observed for house price fluctuations in the data.

Furthermore, the amplitude of the fluctuations generated by interest rate shocks tends to be small compared to the data. The RE model justifies a 4\% appreciation between 2000 and 2005, while the U.S. experienced a tenfold increase over this period. From a RE viewpoint, it thus appears difficult to account for the observed house price dynamics using changes in real interest rates as a driving force.

Even greater difficulties arise if one assumes instead that agents fully anticipate future changes in real interest rates, instead of assuming that any given change is considered permanent. If agents anticipate the 2006 real interest rate increase, then house prices evolve according to the lower line shown in figure 6 . The initial house price increase in 2001 is then even smaller and followed by a gradual decrease, due to the anticipated real rate increase (and house price decrease) in the year 2006. In the data, however, house prices increased strongly after the year 2001.

We can conclude that under RE it is difficult to account for the U.S. house price dynamics using the observed interest rate dynamics. Rather than predicting house price increases over the years 2001-2006, RE predicts that house prices move together with interest rates, that fluctuations are fairly small and that house price persistence is relatively low.

\section{Specifying Near Rational Beliefs}

Under the rational expectations hypothesis, agents are assumed to know that the joint distribution over exogenous shocks and market prices has a singularity

\footnotetext{
${ }^{25}$ Since $\xi_{t}=\xi$, the price-to-rent ratio is simply proportional to the real house price series.' ${ }^{26}$ The intuition for this outcome should become clear from the linear-approximate solution derived in section 5.2.
} 
and where exactly this singularity is located. ${ }^{27}$ Yet, even expert economists rarely agree on the correct economic model linking fundamentals to prices. For this reason it appears of interest to consider agents that face similar doubts and to relax the assumption that agents know the correct model of price behavior.

We shall assume that agents express uncertainty about the true price process by formulating a perceived joint distribution $\mathcal{P}$ over prices and fundamentals. This joint distribution $\mathcal{P}$ does not necessarily have to incorporate a singularity linking house prices to the history of fundaments. Below we construct a specific measure $\mathcal{P}$ deviating from RE beliefs along exactly this dimension. Section 6.1 then shows how one can impose further restrictions that insure that the model outcomes generated by $\mathcal{P}$ are indeed close to the beliefs entertained by agents. And section 6.2 shows that our specification for $\mathcal{P}$ is consistent with the behavior of house prices in the data.

We define the probability space $(\mathcal{B}, \Omega)$ as in section 4.1 . And to simplify the analysis we assume that agents have correct beliefs about all variables except for house prices, i.e., agents hold rational expectations about the exogenous processes $\left\{y_{t}, \xi_{t}\right\}_{t=0}^{\infty}$ and about $\left\{p_{t}=\delta^{-1}\right\}_{t=0}^{\infty} \cdot{ }^{28}$ We relax, however, the assumption that agents believe that average house price growth is equal to zero at all times, as is implied by the approximate REE outcome (24). Instead, we consider agents who believe that the process for house price growth evolves according to

$$
\ln \frac{q_{t}}{q_{t-1}}=\ln \beta_{t}+\ln v_{t}
$$

where $\beta_{t}$ denotes a time-varying persistent component and $v_{t}$ a transitory component. This relaxation of beliefs relative to the REE outcome (24) is motivated by the empirical evidence on house price behavior, which displays periods of persistently increasing prices ( $\ln \beta_{t}>0$ for a number of periods) and periods of persistently falling prices ( $\ln \beta_{t}<0$ for a number of periods).

For simplicity, we shall assume that the persistent component follows a random walk 29

$$
\ln \beta_{t}=\ln \beta_{t-1}+\ln \eta_{t}
$$

and that the innovations are given by

$$
\left(\begin{array}{l}
\ln v_{t} \\
\ln \eta_{t}
\end{array}\right) \sim i i N\left(\left(\begin{array}{c}
0 \\
0
\end{array}\right),\left(\begin{array}{rr}
\sigma_{v}^{2} & 0 \\
0 & \sigma_{\eta}^{2}
\end{array}\right)\right)
$$

Agents' prior beliefs about the persistent component at time zero is assumed normal with

$$
\ln \beta_{0} \sim N\left(\ln m_{0}, \sigma_{0}^{2}\right)
$$

\footnotetext{
${ }^{27}$ This holds true even in a Bayesian Rational Expectations Equilibrium in which agents learn about fundamentals, see Adam and Marcet (2011) for details.

${ }^{28}$ Since the process for $y_{t}$ and $\xi_{t}$ are exogenous to the model, it is straightforward to relax this assumption for these variables.

${ }^{29}$ The fact that $\beta_{t}$ is non-stationary is not important for our results. The model outcome are almost the same when specifying instead a stationary process

$$
\ln \beta_{t}=(1-\rho)+\rho \ln \beta_{t-1}+\ln \eta_{t}
$$

and choosing some value $\rho<1$ that is sufficiently close to one.
} 
and $\sigma_{0}^{2}$ denoting the steady state (Kalman filter) uncertainty, i.e.,

$$
\sigma_{0}^{2}=\frac{-\sigma_{\eta}^{2}+\sqrt{\left(\sigma_{\eta}^{2}\right)^{2}+4 \sigma_{\nu}^{2} \sigma_{\eta}^{2}}}{2}
$$

The prior beliefs (28) together with the process (25)-(27) completely specify agents' beliefs $\mathcal{P}$ about house price behavior.

The present setting gives rise to a learning problem because agents observe the realized house price growth rates $\frac{q_{t}}{q_{t-1}}$, but do not separately observe the persistent component $\beta_{t}$ and the transitory component $v_{t}$. This requires that agents optimally update their beliefs about $\beta_{t}$ in the light of new house price growth observations.

We complete the overall description of $\mathcal{P}$ by assuming that agents know how to map a history of prices into profits. In other words, agents know that profits in $t$ are given by a function $\pi\left(E_{t-1}^{\mathcal{P}} q_{t}, q_{t}\right)$ equal to the right-hand side of equation (8) for $p_{t}=\delta^{-1}$.

\subsection{Insuring Near Rationality of Beliefs}

In this section we impose further restrictions on the beliefs $\mathcal{P}$ of agents to insure that these beliefs are close (in distribution) to the outcomes generated by the model. We thereby proceed as follows. First, we show how to impose restrictions on $\mathcal{P}$ so that these beliefs approach (in distribution) the beliefs entertained by agents in the linearized REE (24) for any given finite amount of time. ${ }^{30}$ Second, as agents' beliefs converge to the REE beliefs, model outcomes equally converge to the REE outcomes (in distribution) because equilibrium prices and quantities are continous functions of agents' beliefs. Since beliefs and model outcomes both converge (in distribution) to the linearized REE outcome (24), agents' beliefs will be approximately validated by the model behavior.

To insure that the beliefs $\mathcal{P}$ are close (in distribution) to the REE beliefs we proceed a follows. First, we center initial beliefs so as to be consistent with the average growth rate of prices in the REE (24), i.e., we choose $m_{0}=1$. Agents thus initially believe that there is no growth in real house prices on average. Second, we consider the case where the innovation variance of the persistent house price component vanishes, i.e., $\sigma_{\eta}^{2} \rightarrow 0$. As a result of this second assumption, prior uncertainty $\sigma_{0}$ about initial price growth also vanishes $\left(\sigma_{0}^{2} \rightarrow 0\right)$. Agents' prior beliefs thus become increasingly concentrated at the point $\beta_{t}=1$. Formally, as $\sigma_{0}^{2} \rightarrow 0$ agents' beliefs about prices converge to the REE beliefs (24) in distribution (or 'in law'). ${ }^{31}$

This shows that for sufficiently small values of $\sigma_{\eta}^{2}$, house price beliefs are indeed close to the model implied beliefs. In our empirical application, we shall consider small but positive values for $\sigma_{\eta}^{2}$. Section 10 then shows that

\footnotetext{
${ }^{30}$ Convergence can only occur for an arbitrarily large but finite horizon because of the unit root present in agents' beliefs.

${ }^{31}$ Again, this holds only for any arbitrarily large but finite horizon.
} 
agents would hardly be able to reject their belief specification for the empirically calibrated value of $\sigma_{\eta}^{2}$.

\subsection{Agents' Beliefs and House Price Behavior in the Data}

This section shows that the belief specification (25)-(26) is also consistent with the behavior of actual house prices in the data. Specifically, we derive testable implications from our belief specification and evaluate to what extent these are consistent with the behavior of the G7 house price data.

The belief equations (25)-(26) imply that $\ln \frac{q_{t}}{q_{t-1}}$ has a unit root and that $\Delta \ln \frac{q_{t}}{q_{t-1}}$ is an $\mathrm{MA}(1)$ process of the form

$$
\Delta \ln \frac{q_{t}}{q_{t-1}}=\ln \eta_{t}+\ln v_{t}-\ln v_{t-1}
$$

Conditional on all the shocks being normally distributed, the fact that $\Delta \ln \frac{q_{t}}{q_{t-1}}$ is an MA(1) process exhausts the empirical implications of the agents' model (25)-(27). ${ }^{32}$

One might be tempted to test (29) using an augmented Dickey-Fuller (ADF) test with a number of lags to capture the fact that $\Delta \ln \frac{q_{t}}{q_{t-1}}$ is serially correlated under the null hypothesis. This approach is problematic, however, because $\sigma_{\eta}^{2}$ is small relative to $\sigma_{\nu}^{2}$ so that the autoregressive coefficients decay only very slowly with the lag length. This would require including a very large number of lags to have a valid ADF test, thereby greatly reducing the degrees of freedom and the power of the test.

A more attractive approach is based on the observation that equation (29) implies

$$
\operatorname{cov}\left(\Delta \ln \frac{q_{t}}{q_{t-1}}, \ln \frac{q_{t-i}}{q_{t-i-1}}\right)=0 \quad \text { for all } i=2,3, \ldots
$$

so that one can run the regression

$$
\Delta \ln \frac{q_{t}}{q_{t-1}}=\sum_{i=2}^{N} \alpha_{i} \ln \frac{q_{t-i}}{q_{t-i-1}}+e_{t}
$$

and test the joint hypothesis that $\alpha_{i}=0$ for $i=2, \ldots, N$. Under the null hypothesis this test is valid for any number of lags $N$. In addition, the hypothesis that $\alpha_{i}=0$ for all $i>1$ is sufficient for $\Delta \ln \frac{q_{t}}{q_{t-1}}$ to be MA(1). The test thus exhausts the empirical implications of the model (25)-(27).

Appendix C explains how we construct a test statistic $W$ to test for the null hypothesis $\alpha_{i}=0(i=2, \ldots, N)$ and that this statistic has a $\chi^{2}$ asymptotic distribution in the case with stationary regressors. Under the agents' model, however, the regressors contain a small non-stationary component, so that we use Monte-Carlo simulations to find the confidence intervals.

\footnotetext{
${ }^{32}$ This is the case because one can recover $\nu_{t}$ and $\eta_{t}$ from the MA process and then find $\beta_{t}$.
} 
Table 6 below reports the test statistic for $N=4$, using data for the years 1970-2008 for each country. The $10 \%$ critical value for $W$ is equal to $6.4 .^{33}$ The results in table 6 thus show that agents would accept their model of house price behavior (25)-(26) in the light of the G7 house price data. ${ }^{34}$

\begin{tabular}{cccccccc}
\hline & US & JAP & GER & FR & ITA & UK & CAN \\
$W$ statistic & 3.6771 & 4.2934 & 4.1107 & 3.6825 & 5.8853 & 3.6530 & 3.7493 \\
\hline
\end{tabular}

Table 6: Testing the Belief Specification Against the Data

\subsection{Internal Rationality and Discounted Sums}

It appears to be a commonly held view among academic economists that rational behavior leaves no room for independent beliefs about prices once beliefs about fundamentals are specified. Individual rationality, so the argument goes, implies that agents know how to formulate prices as discounted sums of future fundamentals. Yet, as discussed in Adam and Marcet (2010), this view is generally incorrect and, as explained below, it also fails to apply for the model studied in the present paper.

Agents with the belief system $\mathcal{P}$ described in the previous section fail to hold enough knowledge to be able to formulate beliefs about prices as a function of their beliefs about fundamentals only. This is the case despite all agents being rational. This can be most easily demonstrated for the case where the nonnegativity constraint on consumption is never binding, so that equation (14) holds each period. Forward iteration on this equation then yields a discounted sum formulation for the house price

$$
q_{t}=E_{t}^{\mathcal{P}} \sum_{j=0}^{\infty} \rho^{j} \xi_{t+j} G^{\prime}\left(H_{t+j}\right)
$$

which holds under internal rationality. Importantly, this discounted sum involves beliefs about future housing decisions $\left(H_{t+j}\right)$, in addition to beliefs about future fundamentals $\left(\xi_{t+j}\right)$. The agent's optimal plan for future $H_{t+j}$, however, is a function of the agent's beliefs about future house prices, so that beliefs about future prices still enter the discounted sum (31). Moreover, since the belief system $\mathcal{P}$ fails to incorporate a singularity linking the future house price

\footnotetext{
${ }^{33}$ The $10 \%$ critial value reported in the text assumes a gain parameter of $g=0.06$, which is the value that we estimate for our model later on. The critical value, however, changes very little over a wide range of values for $g$.

${ }^{34} \mathrm{An}$ alternative test is based on using lags of the price over rent ratio on the right side of the regression (30), which leads to very similar findings. Rent prices, however, are not available for Italy prior to 1996 in our OECD dataset.
} 
to the history of fundamentals, one cannot replace beliefs about future house prices by beliefs about fundamentals only. The agent's price beliefs are thus required to determine the discounted sum (31), while the agent's beliefs about fundamentals are insufficient.

\section{Equilibrium Dynamics with Learning}

We now explore the equilibrium dynamics in an economy in which agents hold the near-REE beliefs $\mathcal{P}$ specified in the previous section. We first derive the evolution of the conditional house price growth expectations $m_{t}$ implied by the probability measure $\mathcal{P}$, then discuss the resulting price dynamics

\subsection{Belief Updating}

Bayesian updating of beliefs implies that agents' posterior beliefs about $\beta_{t}$ at time $t$ are given by

$$
\ln \beta_{t} \sim N\left(\ln m_{t}, \sigma_{0}^{2}\right)
$$

where $\ln m_{t}$ evolves recursively according to

$$
\ln m_{t}=\ln m_{t-1}+g\left(\ln \frac{q_{t}}{q_{t-1}}-\ln m_{t-1}\right)
$$

with the 'gain' parameter given by

$$
g=\frac{\sigma_{0}^{2}}{\sigma_{\nu}^{2}}>0
$$

Agents' conditional expectations of house price growth are then given by

$$
E_{t}^{\mathcal{P}} \frac{q_{t+1}}{q_{t}}=m_{t} e^{\frac{1}{2}\left(\sigma_{0}^{2}+\sigma_{\eta}^{2}+\sigma_{\nu}^{2}\right)} \approx m_{t}
$$

with $m_{t}$ evolving according to equation (32). Furthermore, to avoid simultaneity between price expectations and price outcomes, it is convenient to assume that information on prices is introduced with a delay in $m_{t}$, so that we actually use

$$
\ln m_{t}=\ln m_{t-1}+g\left(\ln \frac{q_{t-1}}{q_{t-2}}-\ln m_{t-1}\right)
$$

A microfounded belief system justifying this delay is provided in proposition 2 in Adam and Marcet (2010).

\subsection{Qualitative Behavior of Equilibrium Prices under Learn- ing}

This section discusses the qualitative behavior of equilibrium house prices under learning. To simplify the discussion we consider the approximate solution when 
linearizing $G$ around its steady state value, so that take $G^{\prime}$ is constant. The asset pricing equation (19) then implies that the equilibrium asset price under learning is (approximately) given by

$$
q_{t}=\frac{\xi_{t} G^{\prime}\left(H^{s s}\right)}{1-\rho m_{t}}
$$

so that realized $\log$ house price growth is

$$
\ln \frac{q_{t}}{q_{t-1}}=\ln \frac{1-\rho m_{t-1}}{1-\rho m_{t}}+\ln \varepsilon_{t}
$$

For the case with vanishing prior uncertainty $\left(\sigma_{\eta}^{2}, \sigma_{0}^{2} \rightarrow 0\right)$, the gain $g$ is small so that $m_{t}$ changes only slowly from period to period. Beliefs then remain close to $m_{t}=1$ for all $t$ in the sample and the above price is well defined because $\rho<1$.

The key feature of house prices under learning is that there is feedback between expectations of price growth and actual price growth. Equation (34) shows that higher expected growth $m_{t}$ leads to higher price and thus higher realized price growth, which in turn increases the expectations tomorrow via the belief updating rule (32). Therefore, the model has the potential to generate price booms that are fueled by the interaction between expectations and realized prices.

This can formally be shown by combining (35) and (33) to obtain a non-linear second order difference equation governing the behavior of $m_{t}$. The dynamics of this difference equation are very similar to those described in section 4.2.1 of Adam, Marcet and Nicolini (2010) for stock prices. They show that price changes display momentum locally around the REE value, i.e., once prices start growing (falling), there is a tendency for prices to continue growing (falling), as well as there being mean reversion in the longer-run.

Within the linearized system, house price increases will come to an end when realized house price growth falls short of the expected price growth. Equation (35) shows that this occurs whenever the increase in price growth optimism becomes too weak to sustain the high level of price growth expectations. For example, if $m_{t}$ is very high, but stays constant from one period to the next $\left(m_{t}=m_{t-1}\right)$, then equation (35) implies that realized price growth is equal to 1 on average, i.e., falls short of expectations.

More generally, the upward price dynamics can come to an end for a number of additional reasons. For example, if there is an increase in real interest rates that causes house prices to increase less than initially expected, or if a negative shock to housing preferences materializes. Finally, the endogenous model dynamics will make it difficult for sustained price increases to continue forever, especially in the more general case with a concave $G$ function. Upward price dynamics and the associated expansion of the housing stock then lead to a fall in $G^{\prime}$ and thereby to a fall in the asset price.

Once price growth realizations fall short of agents' expectations, this sets in motion a sequence of downward belief revisions. Following the initial disappointment, there will be a decrease in price growth expectations, thereby a 
further fall in realized house price growth, i.e., a sequence of downward belief revisions and a price bust. The model thus has the potential to generate a house price boom which eventually will leads to a bust.

\subsection{The Qualitative Response to Interest Rates Changes}

We now explore the effects of an unanticipated decrease in real interest rates in period $t .^{35}$ Equation (35) implies that realized house price growth in period $t$ increases as a result of a reduction in real interest rates. ${ }^{36}$ The price increase is thereby stronger for an economy in which agents in period $t$ are more optimistic about future price growth (in which $m_{t}$ is higher).

After a fall in real interest rates, the initial increase in realized price growth will feed into future beliefs about price growth via the belief updating equation (33). Due to the presence of momentum this leads to a sequence of further increases in realized price growth.

Key to explaining the real house price data shown in figure 5, however, is the fact that interest rates are not the only determinant of whether or not a price boom occurs. If the house price in a given country has been increasing already before the reduction in interest rates, then the interest rate reduction will make it more likely that the house price boom will continue in this country. Conversely, in a country where house prices have been decreasing, the interest rate reduction may only ameliorate the decrease in house prices. Therefore, the model is consistent with the observation that house price booms are not synchronized across countries, even though interest rates behave in a similar way.

A house price boom also relaxes the collateral constraint and leads to an increase in total borrowing, which is given by

$$
b_{t}=\frac{\theta q_{t} m_{t}}{R} H_{t}
$$

House price increases are thus associated with increased international borrowing, i.e., a current account deficit. Provided investment in new houses is not too elastic, the house price boom will also be associated with a consumption boom.

Finally, from equation (6) follows that an increase in expected house price growth leads to an increase in the production of new houses, thereby qualitatively matching the observation about new housing supply displayed in figure 4. Admittedly, the model cannot reproduce the asymmetric and sharp decline in new housing construction after the year 2006. Given the simplicity of the model, however, this should be hardly surprising.

Qualitatively, the previous findings show that the model has the potential to explain a housing boom, that is associated with a current account deficit, a consumption increase and an increase in the production of new housing units. The next sections explore the ability of the learning model to quantitatively

\footnotetext{
${ }^{35}$ Technically, the change in the real interest rate is a probability zero event under the postulated beliefs.

${ }^{36}$ The interest rate enters in the definition of $\rho$, see equation (15)
} 
account for the real house price and current account dynamics in the U.S. and the remaining G7 economies.

\section{The U.S. Experience: 2001-2008}

We now calibrate the learning model to the U.S. economy and show that it can quantitatively replicate the real house price and current account developments for the U.S. economy over the years 2001-2008. The performance for the remaining G7 economies is analyzed in the next section.

We use as data inputs the history of real house prices over the years 19962000 and the stylized path for real interest rates of the years 2001-2008, as captured by the dashed line in figure 2.37 Except for the stylized information about the real interest rate, the predictions we show below do not use any data after the year 2000 .

As in section 5.4, we choose $\theta=0.26, \delta=0.96$ and $d=3 \%$. The gain parameter $g$ in the belief updating equation (33) and second derivative $G^{\prime \prime}$ are chosen to minimize the distance between the model implied prediction for the real house price and the data, we will be more precise about this step in section 9 below. This leads to a annual gain of $g=0.06$, which implies that agents believe that on average $94 \%$ of any observed annual house price increase is transitory in nature.

We set the initial price growth expectations in 1996 as if the model had been in REE for a very long time, i.e., we choose $m_{1996}=1$. We then use the belief updating equation (33) from the model and the real house price growth observation from the U.S. data for the years 1996 to 2000 to impute house price beliefs for the year $2000\left(m_{2000}\right)$. We then use $m_{2000}$ and the real interest rate $R_{1996-2000}$ to compute the equilibrium real house price for the year 2000 . We thereby normalize the equilibrium real house price in the year 2000 to 100 by choosing the value of $\xi G^{\prime}(H)$ correspondingly. ${ }^{38}$ We then use the model to predict the real house price for the years 2001-2008, using as inputs only the interest rate decrease for the years 2001-2005 and the increase for the years 2006-2008.

Figure 7 reports the model-predicted outcome jointly with the U.S. real house price series for the years 2000-2008. The model shows that the decrease in real interest rates in the year 2001 gives rise to an initial increase in the real house price. Since realized price increases feed positively into future beliefs via the updating equation, the initial increase will be followed by further upward price movements, giving rise to a house price boom. The increase comes to

\footnotetext{
${ }^{37}$ Specifically, for the years 1996-2000 we set real interest rates equal to the average ex-ante gross real mortgage rate, i.e., $R_{96-00}=1.0335$. To capture the real interest rate decrease following in years 2001-2005, we set real interest to $R_{01-05}=1.0228$, which is again the average ex-ante U.S. real mortgage rate for this period in the data. Finally, we capture the upward shift in real rates in the years $2006-2008$ by setting $R_{06-08}=1.0301$, which is again taken from the data.

${ }^{38}$ We keep $\xi G^{\prime}(H)$ fixed at this calibrated value in all subsequent model periods. The value for $\xi G^{\prime}(H)$ only normalizes the house price level, but has no impact on the dynamics.
} 


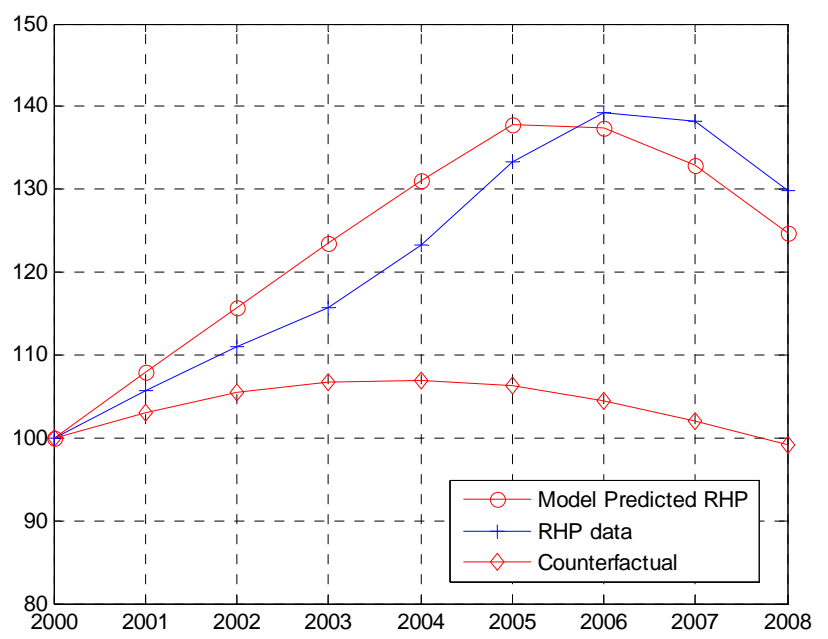

Figure 7: US Real House Prices: Model Predictions, Data and Counterfactual

an end in the year 2006 when interest rates move up again, causing the house price to slowly revert direction, in line with the data. The resulting downward revision in beliefs then sets in motion a sequence of price reductions.

Figure 7 also depicts the model predicted counterfactual house price path that would be obtained if real interest rates in the years 2001-2008 remained at their pre 2001 average. ${ }^{39}$ House prices would then have increased only very mildly. A small increase would have occurred nevertheless, simply because of the positive price momentum that existed already prior to the year 2000. The model is thus consistent with the view that the US housing price boom was mostly caused by interest rates being too low for too long.

The current account dynamics implied by the housing boom in figure 7 depend partly on the long-run housing supply elasticity $\left(\frac{\alpha}{1-\alpha}\right)$, because housing can be used as collateral in international borrowing. For their preferred specification, Topel and Sherwin (1988) estimate a long-run housing supply elasticity of 3 for the United States. Since there is considerable uncertainty about this parameter, we allow for values between 1 and 5 and choose the long-run elasticity that best fits the data, we will be more precise about this below. ${ }^{40}$ The model then prefers a relative elastic supply with $\frac{\alpha}{1-\alpha}=5$. Figure 8 depicts the current account ratio in the data and the one implied by the model. The

\footnotetext{
${ }^{39}$ Gross ex-ante real interest rates are then assumed to stay constant at their 1996-2000 average, which is $R_{96-00}=1.0335$.

40 To obtain a model-implied current account to GDP ratio, one also has to take a stand on the exogenous income process. We choose a time-invariant income, i.e., $y_{t}=y$ so as to match the data.
} 


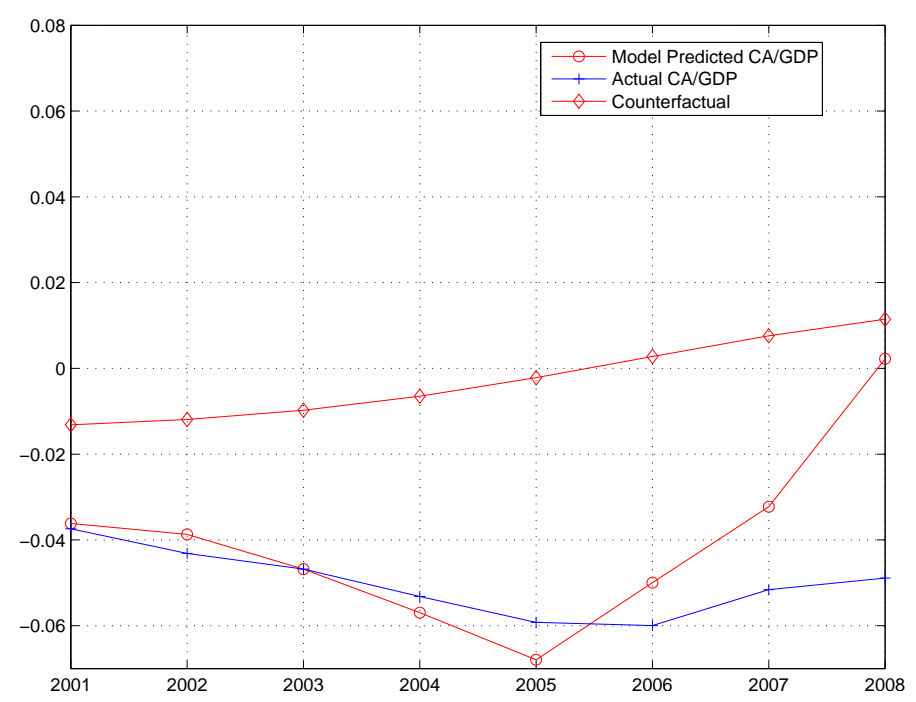

Figure 8: US Current Account Deficit Ratio: Model Predicted and Data

model predicts well the deterioration of the U.S. current account over the years 2001-2005, but overpredicts the improvements following the house price collapse after 2005. Overall, the quantitative performance of the model is surprisingly good, given that it abstracts from so many other factors known to be relevant for the current account, for example, public borrowing.

Figure 8 also depicts the counterfactual reaction of the current account if real interest rate had stayed at their 1996-2000 average. The model predicts that large part of the current account deficits would have been eliminated, had interest rates not decreased after the year 2000. This is the result of a lower volume of collateral and a lower collateral value in the absence of a price and construction boom.

\section{Other G7 Economies: 2001-2008}

We now evaluate the ability of the learning model to explain the real house price and current dynamics over the years 2001-2008 in the remaining G7 economies and we describe in detail the calibration procedure for the parameters $g, G^{\prime \prime}, \alpha, y$. 
JAPAN
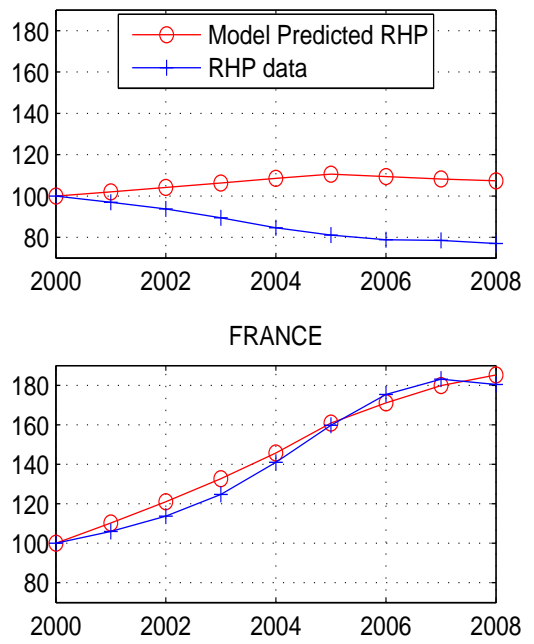

UK

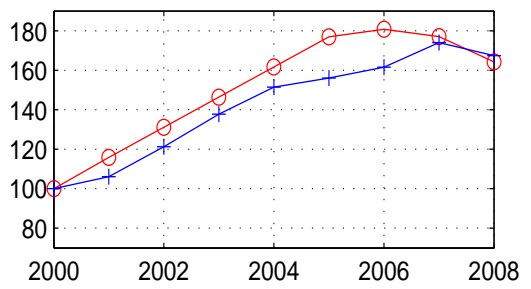

GERMANY
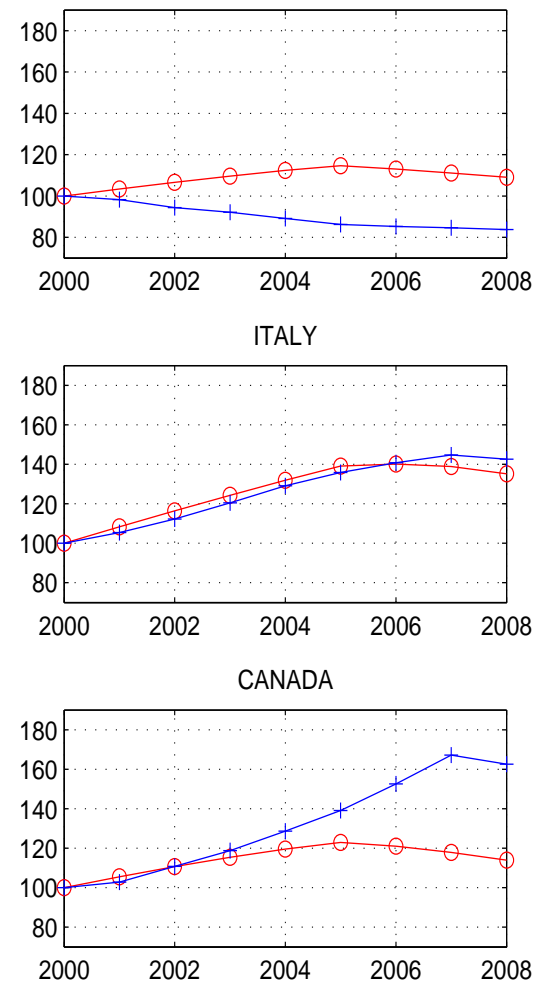

Figure 9: Other G7 Economies: Model Predicted Real House Prices and Real House Price Data 


\subsection{Real House Price Dynamics}

We tie our hands by using the same model parameters for all G7 countries. ${ }^{41}$ We also subject each of the G7 economies to the same stylized interest rate path as the U.S. economy, which amounts to interpreting the U.S. real mortgage rate as a proxy for international real interest rates. Clearly, this approach biases results against us, as we could instead choose to parameterize the model for each country to achieve a better fit with the data. As we show below, the model nevertheless performs surprisingly well.

It is important to note that countries differ because of the method for finding initial beliefs $m_{2000}$, so that the different country-specific house price histories over the years 1996-2000 lead to different imputed beliefs in the year 2000 .

In order to obtain the parameters $g, G^{\prime \prime}, \alpha$ we proceed as follows. We first obtain $\left(g, G^{\prime \prime}\right)$ by minimizing the square deviations between model and actual data. More precisely, letting boldface letters denote actual data, we choose $\left(g, G^{\prime \prime}\right)$ to minimize

$$
\sum_{i=1}^{6} \sum_{t=2000}^{2008}\left(q_{t}^{i}-\mathbf{q}_{t}^{i}\right)^{2}
$$

where $q_{t}^{i}$ is the model implied house price in country $i$ and period $t$ for a given value of parameters. We exclude the UK from this computation, as our experience is that for the value of $g$ that is chosen by this procedure the UK generates an explosive path for prices. Proceeding in this way we obtain the values $g=0.06$ and $G^{\prime \prime}=0$, as mentioned in the previous section. The best match with the data is thus achieved for a linear $G$ function. Yet, to keep our analysis within a well specified model, we impose a minimal amount of curvature by setting $\xi G^{\prime \prime} / G^{\prime}=-0.007 .{ }^{42}$ Next, we determine separately the optimal value for $g$ for the UK, which turns out to be $g=0.046$.

The outcome from simulating the economy with these parameters is depicted in figure 9. It shows that our model predicts strong house price increases for France, Italy, and the U.K., in line with the empirical evidence. The model predicts considerably weaker price increases for Germany and Japan than for the countries mentioned above, albeit it fails to replicate the observed fall in house prices. Since real house prices in Germany and Japan have been falling prior to the year 2000, the presence of momentum in house price changes implies that agents' price growth expectations tend to decrease further. Yet, the interest rate reduction turns this negative momentum into some slight positive momentum. For Canada the model predicts a house price boom, but underpredicts its size, especially at the end of the sample period.

Table 7 below reports for each year the cross-country correlation between the model-predicted real house price and the real house price in the data. The table shows that this correlation is very high throughout. The model thus accounts

\footnotetext{
${ }^{41}$ This is true, except for the value of $\xi G^{\prime}$, which is chosen in each country to normalize the model-implied real house prices in the year 2000 to 100 .

42 The performance of the model deteriorates only slightly, but concavity is required to have an independent role for price beliefs, as explained in section 6.3.
} 
surprisingly well for the asynchronous low frequency movements in house prices, despite the fact that we subject all economies to the same interest rate shocks and use a very parsimonious parameterization.

\begin{tabular}{ccccccccc}
\hline Year & 2001 & 2002 & 2003 & 2004 & 2005 & 2006 & 2007 & 2008 \\
\hline House Price & 0.84 & 0.91 & 0.92 & 0.90 & 0.86 & 0.83 & 0.79 & 0.76
\end{tabular}

Table 7: Yearly Cross-Sectional Correlation Between Model Predicted and

Actual Real House Price for the G7

\subsection{Current Account Dynamics}

We now evaluate the ability of the learning model to explain the current account dynamics for the remaining G7 economies. Using the values of $\left(g, G^{\prime \prime}\right)$ determined in the previous section, we choose the value of the long-run housing supply elasticity $\alpha /(1-\alpha)$ that best fits the observed current account dynamics across countries and periods. We thereby use a an analogous objective function as in the case when matching the house price dynamics. We restrict the search to supply elasticities in the interval $\alpha / 1-\alpha \in[1,5]$ to be consistent with the findings in Topel and Sherwin (1988), as discussed in section 8. Our procedure then chooses the highest admissible value in this interval.

The model is clearly not well suited to explain the level of the current account in all countries. Since the discount factor of domestic households falls short of $R^{-1}$, all countries will want to be borrowers on average, while some countries, e.g., Germany and Japan, are known to have persistent surpluses and also to have accumulated positive net foreign asset positions. Given this, we explore the ability of the model to explain the cyclical movements across time and the overall improvement or worsening of the current account during the studied period.

Table 8 below reports the annual correlation across countries, between the model-implied current account to GDP ratio and the actual current account to GDP ratio, where output $y$ in the model is chosen to be time-invariant and equal to ten times the steady state housing output. As is apparent from the table, the model is able to capture a sizeable part of the current account fluctuations across countries.

\begin{tabular}{ccccccccc}
\hline Year & 2001 & 2002 & 2003 & 2004 & 2005 & 2006 & 2007 & 2008 \\
CA/GDP ratio & 0.47 & 0.57 & 0.53 & 0.60 & 0.61 & 0.57 & 0.49 & 0.30 \\
\hline
\end{tabular}

Table 8: Yearly Cross-Sectional Correlation Between Model Predicted and Actual Current Account/GDP Ratio for the G7

As a further check, we determine the model-implied correlation (across countries) between the total accumulated current account deficit over the period 2000-2007 and house price growth over the same period. In the model this 
correlation equals to -0.98 . In the data this correlation is of the same sign but achieves a lower value of around -.5, depending on the precise measure for house prices used, see table 2 . The fact that the correlation is much higher in the model than in the data arguably reflects the fact that other model-omitted factors have influenced the current account behavior in the data. Introducing such additional factors into the model would most likely reduce the model implied correlation.

\section{Testing the Model Consistency of Beliefs}

This section discusses whether agents in our calibrated model could easily detect that they are using a wrong model to forecast house prices. While outcomes and beliefs are close to each other (in distribution) when $\sigma_{\eta}^{2}$ is sufficiently small, it remains to check that this is indeed the case for the values of $\sigma_{\eta}^{2}$ implied by the calibrated gain parameter $g=0.06$.

We address this issue by assuming that agents apply an econometric test to the data generated by their model (25)-(26) of price behavior. ${ }^{43}$ Specifically, we compute the probability that agents would reject their model of house price behavior using the $W$ test-statistic proposed in section 6.2, which is based on the regression (30). We thereby assume that agents run this test using data for the years 2000-2008 and compute the probability that the model will be rejected when $\xi$ follows a unit root with the estimated standard deviation of $\sigma_{\varepsilon}=0.0115$, which is obtained from data on rental prices. We use 50000 replications of the model under learning with the calibrated parameter values. Table 9 below reports the probability of rejecting the agents' beliefs when testing at the $1 \%$, $5 \%$ and $10 \%$ significance level, respectively. The test uses data generated by the model and confidence intervals for the $W$ statistic obtained from Monte-Carlo simulation for a sample length of 8 model periods (corresponding to the years 2001-2008).

Table 9 shows that the probability of rejecting the model is fairly close to the actual confidence level. Clearly, under rational expectations, the rejection probabilities would exactly equal the corresponding confidence levels. The table thus shows that our learning agents reject their forecasting model with very similar likelihood as agents holding rational expectations who also test their forecasting model.

\begin{tabular}{cccc}
\hline Confidence level & $1 \%$ & $5 \%$ & $10 \%$ \\
Probability of rejecting & 0.0106 & 0.0573 & 0.1251 \\
\hline
\end{tabular}

Table 9: Testing belief specification with $W$ statistic on data generated by the learning model

\footnotetext{
${ }^{43}$ A similar approach has been used in models of learning, see Bray and Savin (1986) for an early reference.
} 


\section{Conclusions}

A simple model of learning can quantitatively account for the G7 house price developments over the recent housing boom and bust period. The model also explains a sizable portion of the cross-sectional dispersion of the G7 current accounts and the correlation between the current account and house prices over time.

The model predicts that a persistent fall in the level of the real interest rate can fuel a persistent and long lasting increase in real house prices. Whether or not such a boom materializes depends crucially on the degree to which agents expect future capital gains already, i.e., on the past price dynamics and shocks hitting the economy.

The model suggests that house price booms can give rise to important welfare distortions because they lead to an over-extension of the housing stock. It thus appears of interest to explore to what extent policy instruments, e.g., adjustments in the permissible leverage ratio or real interest rates can usefully prevent an excessive build-up of the housing stock. The welfare effects of a house price boom thereby depend not only on the size and duration of the house price increase, but also on the underlying elasticity of housing supply.

\section{A Non-negativity constraints on consumption}

We now determine the behavior of the model when the non-negativity constraints on consumption are binding.

Since $\delta R<1$ it is immediate that $c_{0}$ is high and $b_{0}$ is against the borrowing limit as long as the limit is tight enough.

In the main text we supposed that the collateral constraint is binding in all periods. As we show now, this could lead to a violation of the non-negativity constraint on consumption whenever income $y_{t}$ is not high enough. Consider, for example, a case when $E_{j}^{\mathcal{P}} q_{j+1} H_{j}$ has large fluctuations, it is very high at $j=t$ and very low at $j=t+1$. If borrowing is at the collateral limit in both periods, then this implies a large decrease in debt at $t+1$. And if income $y_{t+1}$ is not high enough, this would require negative consumption in $t+1$. The optimal solution then cannot have the feature that the collateral constraint is binding periods $t$ and $t+1$ simultaneously.

In such a situation one can determine the optimal solution as follows. Conjecture that the non-negativity constraint on consumption is binding only in period $t+1$ but not binding in period $t$, so that we have $\gamma_{t}=0$. From the non-binding zero limit in $t$ we have $\lambda_{t}=1$ and from (12) we obtain $\lambda_{t+1}>1$, as $\delta R<1$, so that indeed $c_{t+1}=0$. The binding borrowing constraint at $t+1$ then determines $b_{t+1}$. Using this and the fact that $c_{t+1}=0$ one obtains $b_{t}$ from the budget constraint at $t+1$. The value for $c_{t}$ then follows from the budget constraint at $t$. Moreover, since $\gamma_{t+1}>0$ we can have (12) holding and $\lambda_{t+2}=1$ so that $\mu_{t+2}=0$ and $c_{t+2}>0$, so that from $t+2$ onwards we are back in the case analyzed in the main text where consumption is positive and the collateral 
constraint is binding.

If the previous solution would still imply negative consumption in $t$, then one would have to extend the approach to a setting where consumption is zero for more than one period, say between periods $t+1, \ldots, t+n$. In this case we would have that the collateral constraint being non-binding for $n$ periods, i.e., for periods $t, \ldots, t+n-1$ and one could work backwards to derive a candidate solution in the same manner as described above. Again, after period $t+n$ one would be back in the setting analyzed in the main text.

Therefore, if $E_{j}^{\mathcal{P}} q_{j+1} H_{j}$ is anticipated to be very low in the next period, today's borrowing limit is not binding. All that is required to have an equilibrium where the borrowing limit is always binding is that fluctuations in $E_{j}^{\mathcal{P}} q_{j+1} H_{j}$ are not large and that the parameter $\theta$ is sufficiently low.

\section{B Details for the Linear-Quadratic Approxima- tion}

The main text derives equilibrium quantities under the linear approximation to $G$. We now extend the analysis to a quadratic approximation of $G(\cdot)$. Besides increasing the order of the approximation, this is of interest because it introduces an interaction between housing prices and the level of housing construction. Considering concavity in $G(\cdot)$ is also useful because it makes it less likely that explosive paths for prices will arise under learning: as house prices and new construction increases, the marginal value of housing services $G^{\prime}\left(H_{t}\right)$ decreases, which exerts a dampening effect on the upward prices dynamics under learning.

We show below that the unique locally non-explosive rational expectations (RE) solution then takes the form

$$
\begin{aligned}
\widehat{q}_{t} & =a^{R E} \widehat{\xi}_{t}+b^{R E} \widehat{H}_{t} \\
\widehat{H}_{t+1} & =c^{R E} \widehat{H}_{t}+d^{R E} \widehat{\xi}_{t}
\end{aligned}
$$

where hatted variables denote deviations from the steady state and $\left(a^{R E}, b^{R E}, c^{R E}, d^{R E}\right)$ are given coefficients satisfying $a^{R E}>0, b^{R E}<0,0<c^{R E}<1$ and $d^{R E}>0$.

We now derive a first order accurate approximation to the rational expectations (RE) solution of the equation system

$$
\begin{gathered}
q_{t}=\left(\frac{\theta}{R}+(1-d-\theta) \delta\right) E_{t}^{\mathcal{P}} q_{t+1}+\xi_{t} G^{\prime}\left(H_{t}\right) \\
H_{t+1}=(1-d) H_{t}+S\left(E_{t}^{\mathcal{P}} q_{t+1}, \delta^{-1}\right)
\end{gathered}
$$

We linearize these equations around some steady state $(q, H, \xi)$, i.e., around a point solving the above system of equation for $q_{t}=q, H_{t}=H$ and $\xi_{t}=\xi$ for all $t$. Letting hatted variables again denote deviations from steady state values, a first order approximation to (36) delivers

$$
\widehat{q}_{t}=\rho E_{t}^{\mathcal{P}} \widehat{q}_{t+1}+G^{\prime} \widehat{\xi}_{t}+\xi G^{\prime \prime} \widehat{H}_{t}
$$


where, as in the text, $\rho=\left(\frac{\theta}{R}+(1-d-\theta) \delta\right)$ and with all derivatives evaluated at the steady state. A linearization of (37) delivers

$$
\widehat{H}_{t+1}=(1-d) \widehat{H}_{t}+S^{\prime} E_{t}^{\mathcal{P}} q_{t+1}
$$

We now conjecture a perceived law of motion (PLM) of the form

$$
\widehat{q}_{t}=a \widehat{\xi}_{t}+b \widehat{H}_{t}
$$

With RE and using the law of motion for $\xi_{t}$ we have

$$
E_{t} \widehat{q}_{t+1}=a \widehat{\xi}_{t}+b E_{t} \widehat{H}_{t+1}
$$

Substituting into (39) delivers

$$
\widehat{H}_{t+1}=(1-d) \widehat{H}_{t}+S^{\prime}\left(a \widehat{\xi}_{t}+b E_{t} \widehat{H}_{t+1}\right)
$$

Taking the expectations $E_{t}$ of this equation delivers

$$
E_{t} \widehat{H}_{t+1}=\frac{(1-d)}{\left(1-S^{\prime} b\right)} \widehat{H}_{t}+\frac{S^{\prime} a}{\left(1-S^{\prime} b\right)} \widehat{\xi}_{t}
$$

so that (40) implies

$$
E_{t} \widehat{q}_{t+1}=a \widehat{\xi}_{t}+\frac{(1-d) b}{\left(1-S^{\prime} b\right)} \widehat{H}_{t}+\frac{S^{\prime} a b}{\left(1-S^{\prime} b\right)} \widehat{\xi}_{t}
$$

Substituting this into (38) delivers the actual law of motion (ALM)

$$
\widehat{q}_{t}=\left(\rho a+\rho \frac{S^{\prime} a b}{\left(1-S^{\prime} b\right)}+G^{\prime}\right) \widehat{\xi}_{t}+\left(\rho \frac{(1-d) b}{\left(1-S^{\prime} b\right)}+\xi G^{\prime \prime}\right) \widehat{H}_{t}
$$

Equation coefficients in the ALM and PLM delivers two conditions for $a^{R E}$ and $b^{R E}$ given by

$$
\begin{aligned}
a^{R E} & =\rho a^{R E}+\rho \frac{S^{\prime} a^{R E} b^{R E}}{1-S^{\prime} b^{R E}}+G^{\prime} \\
b^{R E} & =\rho \frac{(1-d) b^{R E}}{1-S^{\prime} b^{R E}}+\xi G^{\prime \prime}
\end{aligned}
$$

The second equation depends only on $b^{R E}$ but is quadratic, the first is linear in $a^{R E}$, conditional on $b^{R E}$.

$$
0=S^{\prime}\left(b^{R E}\right)^{2}+\left(-1+\rho(1-d)-S^{\prime} \xi G^{\prime \prime}\right) b^{R E}+\xi G^{\prime \prime}
$$

which has two solutions

$$
\begin{aligned}
& b_{1}^{*}=\frac{\left(1-\rho(1-d)+S^{\prime} \xi G^{\prime \prime}\right)+\sqrt{\left(-1+\rho(1-d)-S^{\prime} \xi G^{\prime \prime}\right)^{2}-4 S^{\prime} \xi G^{\prime \prime}}}{2 S^{\prime}} \\
& b_{2}^{*}=\frac{\left(1-\rho(1-d)+S^{\prime} \xi G^{\prime \prime}\right)-\sqrt{\left(-1+\rho(1-d)-S^{\prime} \xi G^{\prime \prime}\right)^{2}-4 S^{\prime} \xi G^{\prime \prime}}}{2 S^{\prime}}
\end{aligned}
$$


The corresponding solution for $a$ is

$$
a_{i}^{*}=\frac{G^{\prime}}{1-\frac{\rho}{1-S^{\prime} b_{i}^{*}}}
$$

From (39) and (42) follows that the dynamics for $\widehat{H}_{t}$ are given by

$$
\begin{aligned}
\widehat{H}_{t+1} & =(1-d) \widehat{H}_{t}+S^{\prime} E_{t}^{\mathcal{P}} q_{t+1} \\
& =(1-d) \widehat{H}_{t}+S^{\prime}\left(a_{i}^{*} \widehat{\xi}_{t}+\frac{(1-d) b_{i}^{*}}{\left(1-S^{\prime} b_{i}^{*}\right)} \widehat{H}_{t}+\frac{S^{\prime} a_{i}^{*} b_{i}^{*}}{\left(1-S^{\prime} b_{i}^{*}\right)} \widehat{\xi}_{t}\right) \\
& =\frac{1-d}{1-S^{\prime} b_{i}^{*}} \widehat{H}_{t}+\frac{S^{\prime} a_{i}^{*}}{1-S^{\prime} b_{i}^{*}} \widehat{\xi}_{t}
\end{aligned}
$$

Since $1>d>0$, we have that $S^{\prime} b_{i}^{*}<0$ is a sufficient condition for the dynamics for $\widehat{H}_{t}$ to be locally non-explosive. It is easy to show that the solution $\left(a_{2}^{*}, b_{2}^{*}\right)$ is non-explosive while $\left(a_{1}^{*}, b_{1}^{*}\right)$ implies locally explosive dynamics. Therefore, $\left(a^{R E}, b^{R E}\right)=\left(a_{2}^{*}, b_{2}^{*}\right)$ and $b^{R E}<0$. The values for $\left(c^{R E}, d^{R E}\right)$ follow from equation (44). As we show in the next section, show there exists no other locally non-explosive RE equilibrium.

\section{B.1 Local Uniqueness of the RE Solution}

We now show that there exists no other locally non-explosive RE solution than the one derived in the previous section. We bring the linearized equation (39) and (38) in vector notation:

$$
\left(\begin{array}{rr}
1 & -S^{\prime} \\
0 & \rho
\end{array}\right)\left(\begin{array}{c}
\widehat{H}_{t+1} \\
E_{t}^{\mathcal{P}} \widehat{q}_{t+1}
\end{array}\right)=\left(\begin{array}{cc}
1-d & 0 \\
-\xi G^{\prime \prime} & 1
\end{array}\right)\left(\begin{array}{c}
\widehat{H}_{t} \\
\widehat{q}_{t}
\end{array}\right)+\left(\begin{array}{c}
0 \\
-G^{\prime}
\end{array}\right) \xi_{t}
$$

Inverting the matrix on the left, which is always invertible, we get

$$
\left(\begin{array}{c}
\widehat{H}_{t+1} \\
E_{t}^{\mathcal{P}} \widehat{q}_{t+1}
\end{array}\right)=\left(\begin{array}{cc}
1-\frac{\xi}{\rho} G^{\prime \prime} S^{\prime}-d & \frac{1}{\rho} S^{\prime} \\
-\frac{\xi}{\rho} G^{\prime \prime} & \frac{1}{\rho}
\end{array}\right)\left(\begin{array}{c}
\widehat{H}_{t} \\
\widehat{q}_{t}
\end{array}\right)+\left(\begin{array}{c}
-\frac{1}{\rho} G^{\prime} S^{\prime} \\
-\frac{1}{\rho} G^{\prime}
\end{array}\right)\left(\begin{array}{c}
0 \\
-G^{\prime}
\end{array}\right) \xi_{t}
$$

which is a system with one predetermined and one 'jump' variable. It has a locally unique REE if the first matrix on the right-hand side has one explosive and one stable eigenvalue. The eigenvalues are

$$
\begin{aligned}
& \lambda_{1}=\frac{1}{2 \rho}\left(\rho-d \rho-\xi G^{\prime \prime} S^{\prime}+1+\sqrt{\left(\rho-d \rho-\xi G^{\prime \prime} S^{\prime}+1\right)^{2}+4 \rho(d-1)}\right) \\
& \lambda_{2}=\frac{1}{2 \rho}\left(\rho-d \rho-\xi G^{\prime \prime} S^{\prime}+1-\sqrt{\left(\rho-d \rho-\xi G^{\prime \prime} S^{\prime}+1\right)^{2}+4 \rho(d-1)}\right)
\end{aligned}
$$

It is straightforward to show that $\lambda_{1}$ is unstable $\left(\lambda_{1}>1\right)$ while $\lambda_{2}$ is a stable eigenvalue $\left(-1<\lambda_{2}<1\right)$. 


\section{Test of Agents' Model}

This appendix shows how to design a test statistic for equation (30). Following standard practice in the unit-root literature, the statistic is such that it would be efficient within a certain class of estimators in the stationary case. Consider a version of equation (30)

$$
\Delta \ln \frac{q_{t}}{q_{t-1}}=\alpha^{\prime} x_{t}+e_{t}
$$

where $x_{t}$ is stationary and ergodic, orthogonal to $e_{t}$, and $\Delta \ln \frac{q_{t}}{q_{t-1}}$ is $\operatorname{MA}(1)$. Let $\alpha_{T}^{O L S}$ be the OLS estimator with a sample of $T$ observations. We define the test statistic

$$
\begin{aligned}
W_{T} \equiv & \alpha_{T}^{O L S^{\prime}}\left[\left(X^{\prime} X\right)^{-1} S_{w, T}\left(X^{\prime} X\right)^{-1}\right]^{-1} \alpha_{T}^{O L S} \\
& \text { where } \\
X= & {\left[x_{1}, \ldots, x_{T}\right]^{\prime} } \\
S_{w, T}= & \sum_{t=1}^{T}\left(\Delta \log \frac{q_{t}}{q_{t-1}}\right)^{2} x_{t} x_{t}^{\prime}+\frac{T}{T-1} \sum_{t=2}^{T}\left(\Delta \log \frac{q_{t}}{q_{t-1}}\right)\left(\Delta \log \frac{q_{t-1}}{q_{t-2}}\right) x_{t} x_{t-1}^{\prime} \\
& +\frac{T}{T-1} \sum_{t=1}^{T-1}\left(\Delta \log \frac{q_{t}}{q_{t-1}}\right)\left(\Delta \log \frac{q_{t+1}}{q_{t}}\right) x_{t} x_{t+1}^{\prime}
\end{aligned}
$$

Clearly $\frac{1}{T} S_{w, T}$ is a consistent estimator of the spectral density evaluated at frequency zero when $e_{t}$ is $\mathrm{MA}(1)$ and independent of $x_{t}$.

Using standard results it can be shown that under the null hypothesis $(\alpha=0)$ we have

$$
W_{T} \rightarrow \chi_{3}^{2} \text { in distribution as } T \rightarrow \infty
$$

Clearly, this asymptotic result cannot be applied to testing equation (30), since the regressors in (30) are non-stationary. We therefore derive correct confidence intervals for $W_{T}$ by Monte-Carlo simulation for a given sample size $T$ and given parameter values (the confidence intervals turn out not to be very different from those of a $\chi^{2}$ distribution). The set of parameters consists only of the variances $\sigma_{\eta}^{2}$ and $\sigma_{v}^{2}$, so that it is easy to test for the sensitivity of the confidence intervals. We find that the main results would be non-altered for a wide range of values for these variances.

\section{References}

Adam, K., And A. Marcet (2010): "Booms and Busts in Asset Prices," London School of Economics mimeo.

(2011): "Internal Rationality, Imperfect Market Knowledge and Asset Prices," Journal of Economic Theory, 146, 1224-1252. 
Adam, K., A. Marcet, and J. P. Nicolini (2010): "Learning and Stock Market Volatility," Mannheim University Mimeo.

Aizenmann, J., and Y. Jinjarak (2009): "Current Account Patterns and National Real Estate Markets," Journal of Urban Economics, 66, 75-89.

Bray, M., and N. Savin (1986): "Rational Expectations, Equilibria, Learning, and Model Specification," Econometrica, 54, 1129-1160.

Burnside, C., M. Eichenbaum, and S. Rebelo (2011): "Understanding Booms and Busts in Housing Markets," Northwestern University mimeo.

Gete, P. (2010): "Housing Markets and Current Account Dynamics," Georgetown University mimeo.

Glaeser, E., and J. Gyourko (2006): "Housing Dynamics," NBER Working Paper 1278\%.

Glaeser, E., J. Gyourko, and A. Saiz (2008): "Housing Supply and Housing Bubbles," Harvard University mimeo.

Himmelberg, C., C. Mayer, and T. Sinai (2005): "Assessing High House Prices: Bubbles, Fundamentals, and Misperceptions," Journal of Economic Perspectives, 19(4), 67-92.

Iacoviello, M. (2005): "House Prices, Borrowing Constraints and Monetary Policy in the Business Cycle," American Economic Review, 95, 739-764.

Kiyotaki, N., and J. Moore (1997): "Credit Cycles," Journal of Political Economy, 105, 211-248.

Laibson, D., and J. Mollerstrom (2010): "Capital Flows, Consumption Booms and Asset Bubbles: A Behavioural Alternative to the Savings Glut Hypothesis," Economic Journal (forthcoming).

Lustig, H., and S. V. Nieuwerburgh (2005): "Housing Collateral, Consumption Insurance, and Risk Premia: An Empirical Perspective," Journal of Finance, 60, 1167-1219.

Matsuyama, K. (1990): "Residential Investment and the Current Account," Journal of International Economics, 28, 137-153.

Piazzesi, M., And M. Schneider (2009): "Momentum Traders in the Housing Market: Survey Evidence and a Search Model," American Economic Review, Papers and Proceedings, 99, 406-411.

Punzi, M. T. (2006): "Housing Market and Current Account Imbalances in the International Economy," University of Alicante mimeo.

Topel, R., and S. Rosen (1988): "Housing Investment in the United States," Journal of Political Economy, 96, 718-740. 